\title{
Multiphysics Computational Analysis of a Solid-Core Nuclear Thermal Engine Thrust Chamber
}

\author{
Ten-See Wang ${ }^{1}$ and Francisco Canabal ${ }^{2}$ \\ NASA Marshall Space Flight Center, Huntsville, Alabama, 35812 \\ Gary Cheng ${ }^{3}$ \\ University of Alabama at Birmingham, Birmingham, Alabama, 35294 \\ and \\ Yen-Sen Chen ${ }^{4}$ \\ Engineering Sciences, Inc., Huntsville, Alabama, 35815
}

\begin{abstract}
The objective of this effort is to develop an efficient and accurate computational heat transfer methodology to predict thermal, fluid, and hydrogen environments for a hypothetical solid-core, nuclear thermal engine - the Small Engine. In addition, the effects of power profile and hydrogen conversion on heat transfer efficiency and thrust performance were also investigated. The computational methodology is based on an unstructured-grid, pressure-based, all speeds, chemically reacting, computational fluid dynamics platform, while formulations of conjugate heat transfer were implemented to describe the heat transfer from solid to hydrogen inside the solid-core reactor. The computational domain covers the entire thrust chamber so that the afore-mentioned heat transfer effects impact the thrust performance directly. The result shows that the computed core-exit gas temperature, specific impulse, and core pressure drop agree well with those of design data for the Small Engine. Finite-rate chemistry is very important in predicting the proper energy balance as naturally occurring hydrogen decomposition is endothermic. Locally strong hydrogen conversion associated with centralized power profile gives poor heat transfer efficiency and lower thrust performance. On the other hand, uniform hydrogen conversion associated with a more uniform radial power profile achieves higher heat transfer efficiency, and higher thrust performance.
\end{abstract}

\section{Nomenclature}

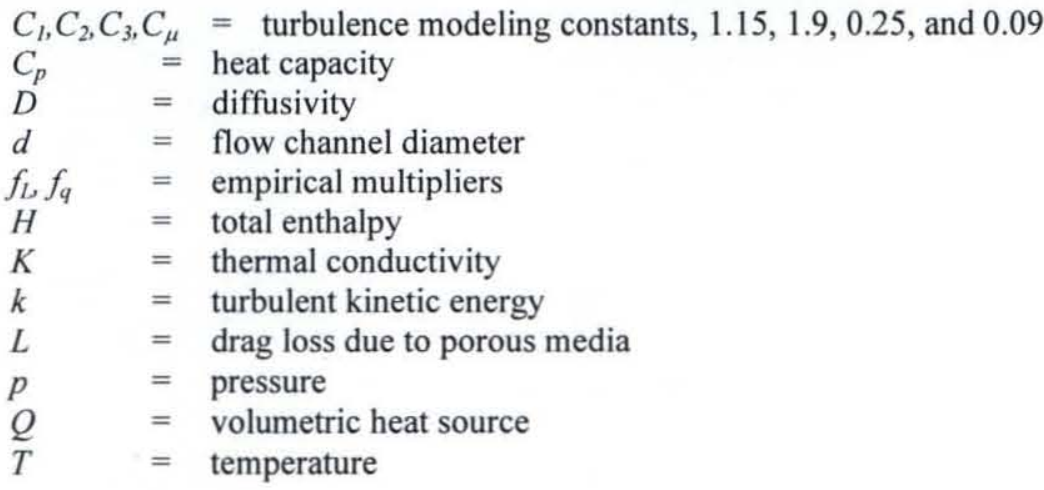

\footnotetext{
${ }^{1}$ Technical Assistant, ER43, Thermal and Combustion Analysis Branch, Senior Member AIAA.

${ }^{2}$ Project Engineer, EV33, Aerosciences Branch, Member AIAA.

${ }^{3}$ Associate Professor, Department of Mechanical Engineering, Senior Member AIAA.

${ }^{4}$ President, Member AIAA.
} 


$\begin{array}{ll}t & =\text { time, } \mathrm{s} \\ U & =\text { flow speed } \\ u_{i} & =\text { mean velocities in three directions } \\ x & =\text { Cartesian coordinates } \\ \alpha & =\text { species mass fraction } \\ \beta & =\text { porosity or void of fraction } \\ \varepsilon & =\text { turbulent kinetic energy dissipation rate } \\ \theta & =\text { energy dissipation contribution } \\ \mu & =\text { viscosity } \\ \mu & =\text { turbulent eddy viscosity }\left(=\rho \mathrm{C}_{\mu} \mathrm{k}^{2} / \varepsilon\right) \\ \Pi & =\text { turbulent kinetic energy production } \\ \rho & =\text { density } \\ \sigma & =\text { turbulence modeling constants } \\ \tau & =\text { shear stress } \\ \omega & =\text { chemical species production rate }\end{array}$

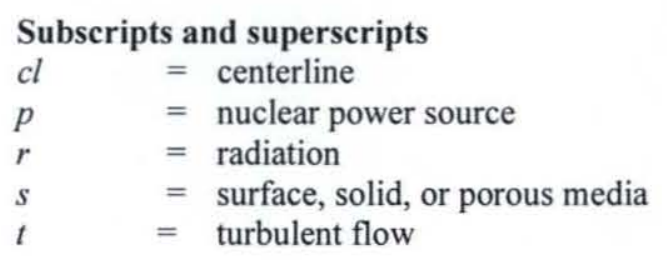

\section{Introduction}

$\mathrm{N}^{w}$ uclear thermal propulsion ${ }^{1}$ can carry far larger payloads and reduce travel time for astronauts traveling to Mars than is now possible with chemical propulsion. One of the feasible concepts, extensively tested during the Rover/NERVA era, is the solid-core concept. ${ }^{2}$ It features a solid-core nuclear reactor consisting of hundreds of heat generating prismatic flow elements, each containing tens of tubular flow channels through which the working fluid, hydrogen, acquires energy and expands in a high expansion nozzle to generate thrust.

The advantage of using hydrogen as a propellant is well known in the chemical rocket due to its low molecular weight. The effect of using hydrogen as a working fluid in a nuclear heat exchanger however, is not well studied. For example, molecular hydrogen decomposes to atomic hydrogen during high temperature heating. Since atomic hydrogen has half the weight of that of molecular hydrogen, it was speculated that the total thrust could be doubled if all of the hydrogen is converted at very high temperatures. In actuality, the hydrogen conversion is probably not uniform across the solid-core since the reactor temperature depends on the hydrogen flow rate distribution and the power profile, which is a function of the Uranium loading. In addition, the hydrogen atom could recombine in the nozzle since temperature decreases rapidly during the gas expansion.

On the other hand, it is always desirable to decrease the reactor weight while one of the ideas is to reduce the reactor size, which increases the power density. One of the impacts of operating at the combination of high temperature and high power density is a phenomenon known as the mid-section corrosion, as reported during the legacy engine tests. ${ }^{2,3}$ It is the cracking of the coating layer, coupled with an excessive mass loss of the material near the mid-section of a flow element. The purpose of the coating layer was to isolate the carbonaceous compound in the flow element matrix from the attack by hydrogen. The causes of mid-section corrosion were speculated as a mismatch in the thermal expansion of flow element and its coating material, high flow element web internal temperature gradients, and change of solid thermal property due to irradiation. ${ }^{4}$

Moreover, reduction of reactor size often started with reducing the diameter of the flow channels, which results in high aspect ratio, or long flow channels. According to Rayleigh line theory, flow with continuous heat addition in a long tube could choke. When that happens, any further heat addition can only serve to reduce the mass flow rate in the tube or, in other words, to jump to another Rayleigh line of lower mass flow. ${ }^{5}$ This could cause unintended mass flow mal-distribution, resulting in side load in the flow element matrix and cracking the coating material. Choking in the heated long flow channel is therefore another possibility causing mid-section corrosion.

To better understand the afore-mentioned design issues, to help the design of the ongoing test apparatus for materials development, ${ }^{4,6}$ and to aim for the future thrust chamber design analyses, the objective of this effort is to develop an efficient and accurate multiphysics computational heat transfer methodology, capable of providing environments for studying those tasks. A unified thermal flowfied of a hypothetical solid-core thrust chamber from 
the Small Engine ${ }^{7}$ was computed as a first attempt in this effort. The Small Engine was a 'paper engine' designed near the end of the Rover/NERVA era that bears features of most legacy engines tested during that time period, but was never built nor tested. By simulating and comparing the computed environments with those of the Small Engine design analysis and available test information from other legacy tests, the lessons learned during Rover/NERVA era may be revitalized and new strategy for reactor design and materials development devised.

A two-pronged approach was conducted, a detailed modeling of a single, powered flow element that could address the possible causes of the mid-section corrosion, is reported in a separate effort ${ }^{8}$, and a global modeling approach that computes the entire thermal flowfield of the Small Engine thrust chamber, is reported here. The global approach solves the entire thrust chamber with detailed modeling, except the thousands of flow channels in the hundreds of flow elements were lumped together as a porous media, for computational efficiency. Specific impulse, core-exit gas temperature, and pressure drop were computed and compared with those of the Small Engine. In total, five three-dimensional thrust chamber computations were performed, to study the effects of hydrogen conversion and its relationship with power profiles on overall heat transfer efficiency and thrust performance.

\section{Computational Heat Transfer Methodology}

\section{A. Fluid Dynamics}

The computational methodology was based on a multi-dimensional, finite-volume, viscous, chemically reacting, unstructured grid, and pressure-based, computational fluid dynamics formulation. ${ }^{9}$ Time-varying transport equations of continuity, species continuity , momentum, total enthalpy, turbulent kinetic energy, and turbulent kinetic energy dissipation were solved using a time-marching sub-iteration scheme and are written as:

$$
\begin{aligned}
& \frac{\partial \rho}{\partial t}+\frac{\partial}{\partial x_{j}}\left(\rho u_{j}\right)=0 \\
& \frac{\partial \rho \alpha_{i}}{\partial t}+\frac{\partial}{\partial x_{j}}\left(\rho u_{j} \alpha_{j}\right)=\frac{\partial}{\partial x_{j}}\left[\left(\rho D+\frac{\mu_{t}}{\sigma_{\alpha}}\right) \frac{\partial \alpha_{i}}{\partial x_{j}}\right]+\omega_{i} \\
& \frac{\partial \rho u_{i}}{\partial t}+\frac{\partial}{\partial x_{j}}\left(\rho u_{j} u_{i}\right)=-\frac{\partial p}{\partial x_{i}}+\frac{\partial \tau_{i j}}{\partial x_{j}} \\
& \frac{\partial \rho H}{\partial t}+\frac{\partial}{\partial x_{j}}\left(\rho u_{j} H\right)=\frac{\partial p}{\partial t}+Q_{r}+\frac{\partial}{\partial x_{j}}\left(\left(\frac{K}{C_{p}}+\frac{\mu_{t}}{\sigma_{H}}\right) \nabla H\right)+\frac{\partial}{\partial x_{j}}\left(\left(\left(\mu+\mu_{t}\right)-\left(\frac{K}{C_{p}}+\frac{\mu_{t}}{\sigma_{H}}\right)\right) \nabla\left(V^{2} / 2\right)\right)+\theta \\
& \frac{\partial \rho k}{\partial t}+\frac{\partial}{\partial x_{j}}\left(\rho u_{j} k\right)=\frac{\partial}{\partial x_{j}}\left[\left(\mu+\frac{\mu_{t}}{\sigma_{k}}\right) \frac{\partial k}{\partial x_{j}}\right]+\rho(\Pi-\varepsilon) \\
& \frac{\partial \rho \varepsilon}{\partial t}+\frac{\partial}{\partial x_{j}}\left(\rho u_{j} \varepsilon\right)=\frac{\partial}{\partial x_{j}}\left[\left(\mu+\frac{\mu_{t}}{\sigma_{\varepsilon}}\right) \frac{\partial \varepsilon}{\partial x_{j}}\right]+\rho \frac{\varepsilon}{k}\left(C_{1} \Pi-C_{2} \varepsilon+C_{3} \Pi^{2} / \varepsilon\right)
\end{aligned}
$$

A predictor and corrector solution algorithm was employed to provide coupling of the governing equations. A second-order central-difference scheme was employed to discretize the diffusion fluxes and source terms. For the convective terms, a second-order upwind total variation diminishing difference scheme was used. To enhance the temporal accuracy, a second-order backward difference scheme was employed to discretize the temporal terms. Details of the numerical algorithm can be found in Ref's 9-13.

An extended $k-\varepsilon$ turbulence model ${ }^{14}$ was used to describe the turbulent flow and turbulent heat transfer. A modified wall function approach was employed to provide wall boundary layer solutions that are less sensitive to the near-wall grid spacing. Consequently, the model has combined the advantages of both the integrated-to-the-wall approach and the conventional law-of-the-wall approach by incorporating a complete velocity profile and a universal temperature profile?

\section{B. Heat Transfer in Solids}

The solid heat conduction equation was solved with the gas-side heat flux distributions as its boundary conditions.

The solid heat conduction equation can be written as: 


$$
\frac{\partial \rho C_{p} T_{s}}{\partial t}=\frac{\partial}{\partial x_{j}}\left(K \frac{\partial T_{s}}{\partial x_{i}}\right)+Q_{p}+Q_{s}
$$

\section{Flow and Heat Transfer in Porous Media}

A two-temperature porosity model was formulated and separate thermal conductivities for the flow and the solid parts were used. The heat transfer between the flow and solid was modeled by using the empirical correlation of heat transfer coefficient for circular pipes as a function of flow Reynolds numbers. Empirical multipliers for both the heat transfer and drag loss were determined by comparing solutions of flow passing through a porous flow element with those of a Small Engine 19-channel flow element using detailed conjugate heat transfer modeling. The only affected fluid governing equations are Navier-Stokes and energy equations and can be rewritten as:

$$
\begin{aligned}
& \frac{\partial \rho u_{i}}{\partial t}+\frac{\partial}{\partial x_{j}}\left(\rho u_{j} u_{i}\right)=-\frac{\partial p}{\partial x_{i}}+\frac{\partial \tau_{i j}}{\partial x_{j}}-\frac{L}{\beta} \\
& \frac{\partial \rho H}{\partial t}+\frac{\partial}{\partial x_{j}}\left(\rho u_{j} H\right)=\frac{\partial p}{\partial t}+Q_{r}+\frac{\partial}{\partial x_{j}}\left(\left(\frac{K}{C_{p}}+\frac{\mu_{t}}{\sigma_{H}}\right) \nabla H\right)+\frac{\partial}{\partial x_{j}}\left(\left(\left(\mu+\mu_{t}\right)-\left(\frac{K}{C_{p}}+\frac{\mu_{t}}{\sigma_{H}}\right)\right) \nabla\left(V^{2} / 2\right)\right)+\theta+\frac{1}{\beta} Q_{s}
\end{aligned}
$$

For the solid heat conduction in porous media,

$$
\frac{\partial \rho_{s} C_{p s} T_{s}}{\partial t}=\frac{\partial}{\partial x_{j}}\left(K_{s} \frac{\partial T_{s}}{\partial x_{i}}\right)+\frac{1}{1-\beta}\left(Q_{p}-Q_{s}\right)
$$

For the Small Engine 19-channel flow element heat-exchanger configuration, drag loss in circular pipes can be used as a point of departure. That is,

$$
L=\frac{1}{2} \rho f_{L} c_{f}|U| \cdot u_{i} / d
$$

where $c_{f}=0.0791 \mathrm{Re}^{-0.25}$ is the Blasius formula for turbulent pipe flow. ${ }^{15}$

For the heat exchange source term,

$$
Q_{s}=\frac{1}{2} \rho f_{q} \frac{c_{f}}{p_{r}^{2 / 3}}|U| C_{p}\left(T_{s}-T\right) / d
$$

For the purpose of this study, the conjugate heat transfer module for solids was benchmarked with the analysis of a cylindrical specimen heated by an impinging hot hydrogen jet. ${ }^{4}$ The computed solid temperature profiles agreed well with those of a standard solid heat transfer code SINDA. ${ }^{16}$ The methodology for flow through porous media was verified through a particle-bed nuclear flow element ${ }^{17}$ and the Space Shuttle Main Engine (SSME) main injector assembly. ${ }^{18}$ The numerical and physical models for predicting the thrust and wall heat transfer were benchmarked with an analysis of the SSME thrust chamber flowfield, in which the computed axial-thrust performance, flow features, and wall heat fluxes compared well with those of the test data. ${ }^{12}$

\section{Three-Dimensional Thrust Chamber Modeling}

The flow and heat transfer inside a solid-core thrust chamber was modeled after the Small Engine. ${ }^{7}$ General geometry and operating conditions were obtained from Ref. 7, while certain specific operating conditions and nozzle geometry were provided by the System Engineering group.

\section{A. Computational Grid Generation}

Hybrid computational grids were generated using a software package GRIDGEN ${ }^{19}$. There are 564 flow elements and 241 support elements or tie-tubes designed for the solid-core reactor in the Small Engine. The prismatic flow 
element contains 19 tubular coolant channels. Each flow element is held in position by three tie-tubes and the corresponding hot-end support system (not modeled). The layout of the flow elements and tie-tubes of the solid-core is such that the whole thrust chamber is symmetrical about a $30 \mathrm{deg}$. pie-shaped section. A total of 1,925,742 grid points or 2,408,198 computational cells were used. Figure 1 shows a $240 \mathrm{deg}$. view of the computational grid and geometry layout of the thrust chamber and tie-tube walls. The thrust chamber includes the inlet wall, the pressure vessel, and the nozzle with skirt, while the expansion ratio is 100 . Only tie-tubes in the pressure vessel are shown for clarity. Figure 2 shows a cross-sectional cut of the solid-core computational grid depicting flow elements, tie-tubes, slat, and reflector. Note that the 19 channels in each flow element were lumped as one porous flow channel, and the effect of which were modeled with Eq. (8) through Eq. (12).

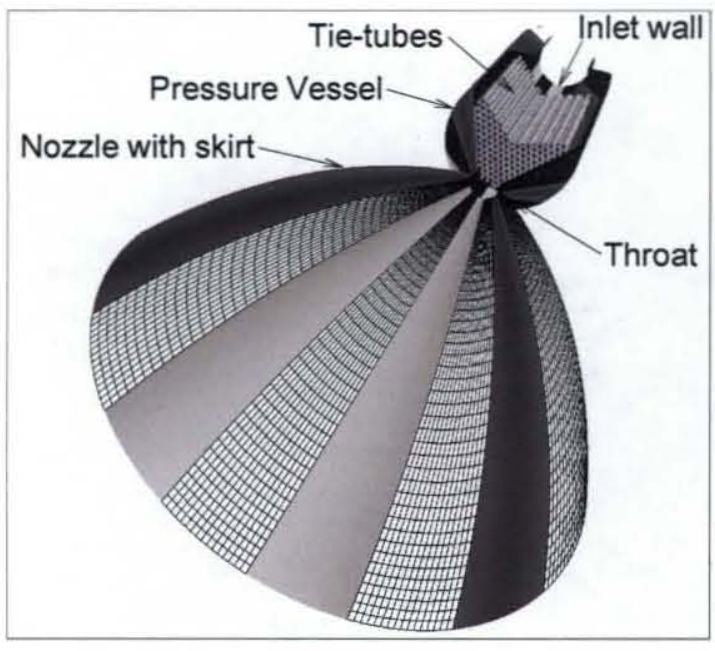

Fig. 1 Computational grid and geometry representation of the solid-core Small Engine thrust chamber.

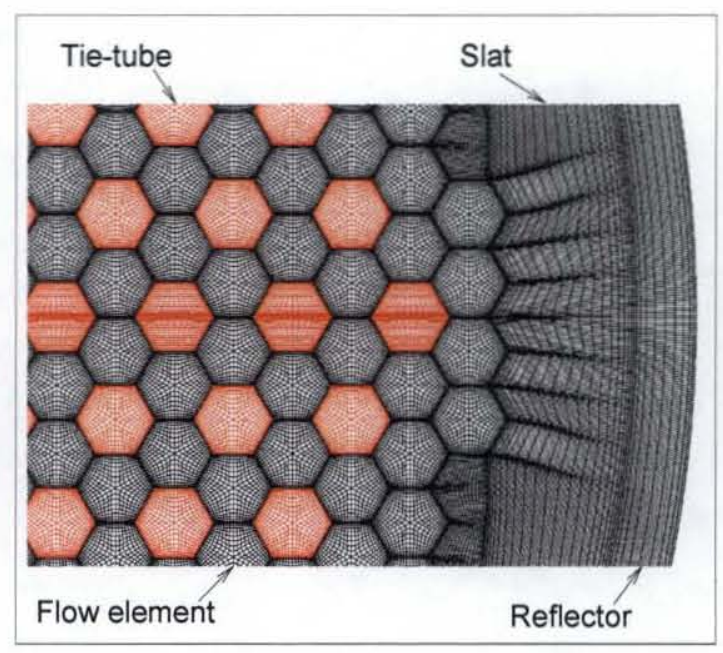

Fig. 2 Cross-sectional computational grid layout for the solid-core of the Small Engine.

\section{B. Thermal Properties and Kinetics}

Real gas thermodynamic properties were obtained from Ref. 20. These properties were generated for temperatures up to $20,000 \mathrm{deg}$. $\mathrm{K}$. The peak gas temperature computed did not exceed $10,000 \mathrm{deg}$. $\mathrm{K}$, hence well within the applicable range. A 2-species, 2-reaction chemical kinetics mechanism was used to describe the finite-rate hydrogen dissociation and recombination reactions, as shown in Table 1. The first hydrogen recombination reaction is abridged from a large set of mechanism for kerosene combustion, ${ }^{21}$ while an irreversible, second reaction ${ }^{22}$ is added to describe the hydrogen decomposition.

Table 1 Hydrogen reaction kinetics mechanism

\begin{tabular}{|c|c|c|c|c|c|}
\hline Reaction $^{\mathrm{a}}$ & A & B & E/R & M & Ref. \\
\hline $\mathrm{M}+\mathrm{H}+\mathrm{H}=\mathrm{H}_{2}+\mathrm{M}$ & $5.0 \mathrm{E} 15$ & 0 & 0 & $\mathrm{H}_{2}, \mathrm{H}$ & 20 \\
\hline $\mathrm{M}+\mathrm{H}_{2} \rightarrow \mathrm{H}+\mathrm{H}+\mathrm{M}$ & $8.8 \mathrm{E} 14$ & 0 & 48300 & $\mathrm{H}_{2}$ & 21 \\
\hline
\end{tabular}

${ }^{\mathrm{a}} \mathrm{M}$ is third-body collision partner and rate constant $\mathrm{K}=\mathrm{AT}^{\mathrm{B}} \exp (-\mathrm{E} / \mathrm{RT})$.

Solid-core flow element material is assumed to be the $(\mathrm{U}, \mathrm{Zr}) \mathrm{C}$-graphite composite A which was tested as flow element material in the Nuclear Furnace 1 Test Reactor. Properties of thermal conductivity, density, and heat capacity as a function of temperature were obtained for $(\mathrm{U}, \mathrm{Zr}) \mathrm{C}$-graphite composite A from Ref. 3. Those properties $^{23}$ of Beryllium were used for the reflector and slat. Slat acts as a buffer between the core and the reflector.

\section{Boundary, Inlet Conditions and Run Matrix}

No-slip boundary condition was applied to all solid walls, while supersonic outflow boundary condition was employed at the nozzle exit. Total conditions were used at the inlet. Inlet hydrogen flow properties were obtained from a 
system model simulation. Since the minor thermal effects of tie-tubes were included in the system model simulation, adiabatic wall boundary condition was used for tie-tube walls in lieu of modeling the heat transfer inside the tie-tubes. The core surrounding components such as the slat and reflector were treated as heat conducting solids to provide accurate boundary condition for the solid-core boundary. The heat conducted from the core through slat and reflector to the outer thrust chamber walls was dissipated to a far-field temperature of $310 \mathrm{~K}$.

Power profiles were imposed onto the solid-core domain in lieu of the neutronics calculations. Two axial and three radial power profiles were used to show the effect of which on the heat transfer and thrust performance, as shown in Figs. 3 and 4. The run matrix is formed with three combinations of these power profiles, as shown in Table 2. The first combination uses the shape of a Cosine curve in both the axial and radial directions which resembles the thermal flux distribution in bare reactors, ${ }^{23}$ and is simply named as the Cosine-Cosine power profile. By definition, the power of the Cosine-Cosine power profile peaks at the middle of the core and drops to zero at the core boundary due to escaping neutrons. The second one is prescribed by a neutronics calculation with varied Uranium loading. It gives a clipped

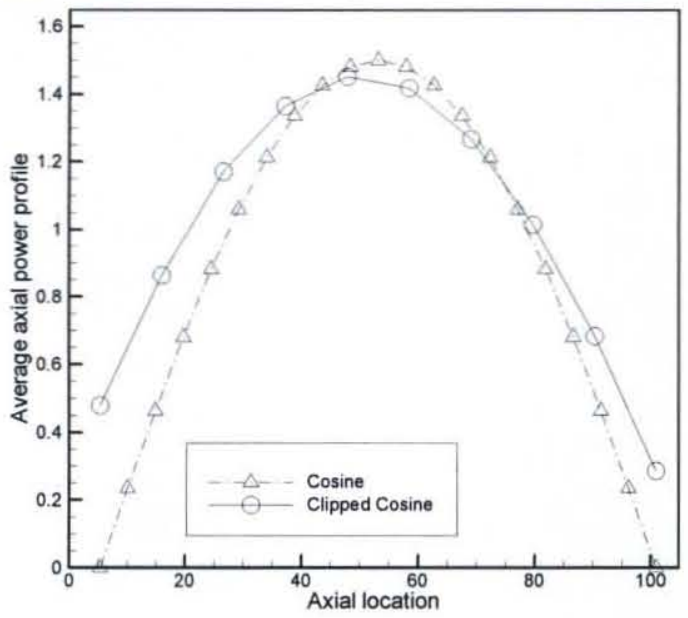

Fig. 3 Power profiles used in the axial direction.

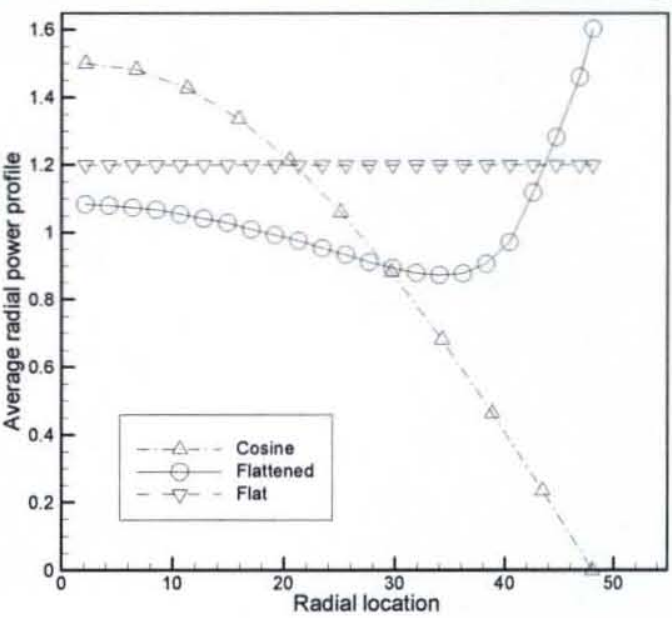

Fig. 4 Power profiles employed in the radial direction.

Cosine profile in the axial direction and a flattened profile in the radial direction, and is dubbed as the clipped Cosineflattened power profile. The varied Uranium loading flattens the power profile in the radial direction, but the power rises near the boundary to show the effect of the reflector, as shown in Fig. 4. The idea of flattening the radial profile is such that the flow in the channels is heated more uniformly, thereby improving the heat transfer efficiency. The clipped Cosine-flattened profile probably represents the closest power profile to what would have happened in the Small Engine. To see the effect of a theoretically flat radial power distribution, the third combination employs the clipped Cosine curve in the axial direction and a flat curve in the radial direction, which is called the clipped Cosine-flat power profile.

In total, five cases were computed in this study, as shown in Table 2. To understand the effect of hydrogen conversion on the heat transfer and thrust performance, finite-rate and frozen chemistries were applied to the CosineCosine power profile separately as Cases 1 and 2, while those were applied to the clipped Cosine-flattened power distribution respectively as Cases 3 and 4 . Finite-rate chemistry means the hydrogen decomposition and recombination reactions were invoked while the reaction rate is finite, as shown in Table 1 . When finite-rate chemistry is used, the species composition is a function of the local temperature, pressure, and residence time. Frozen chemistry means the inlet composition is frozen and chemical reactions are not allowed.

Table 2 Run matrix.

\begin{tabular}{|c|c|c|c|}
\hline Case & Axial power shape & Radial power shape & Chemistry \\
\hline 1 & Cosine & Cosine & Finite-rate \\
\hline 2 & Cosine & Cosine & Frozen \\
\hline 3 & Clipped Cosine & Flattened & Finite-rate \\
\hline 4 & Clipped Cosine & Flattened & frozen \\
\hline 5 & Clipped Cosine & Flat & Finite-rate \\
\hline
\end{tabular}




\section{Results and Discussion}

Case 1: Cosine-Cosine power profile, finite-rate chemistry

Figure 5 shows the computed thrust chamber temperatures, and hydrogen atom mass fraction contours for the Cosine-Cosine power distribution with finite-rate chemistry case. In the temperature contours plot, those in the

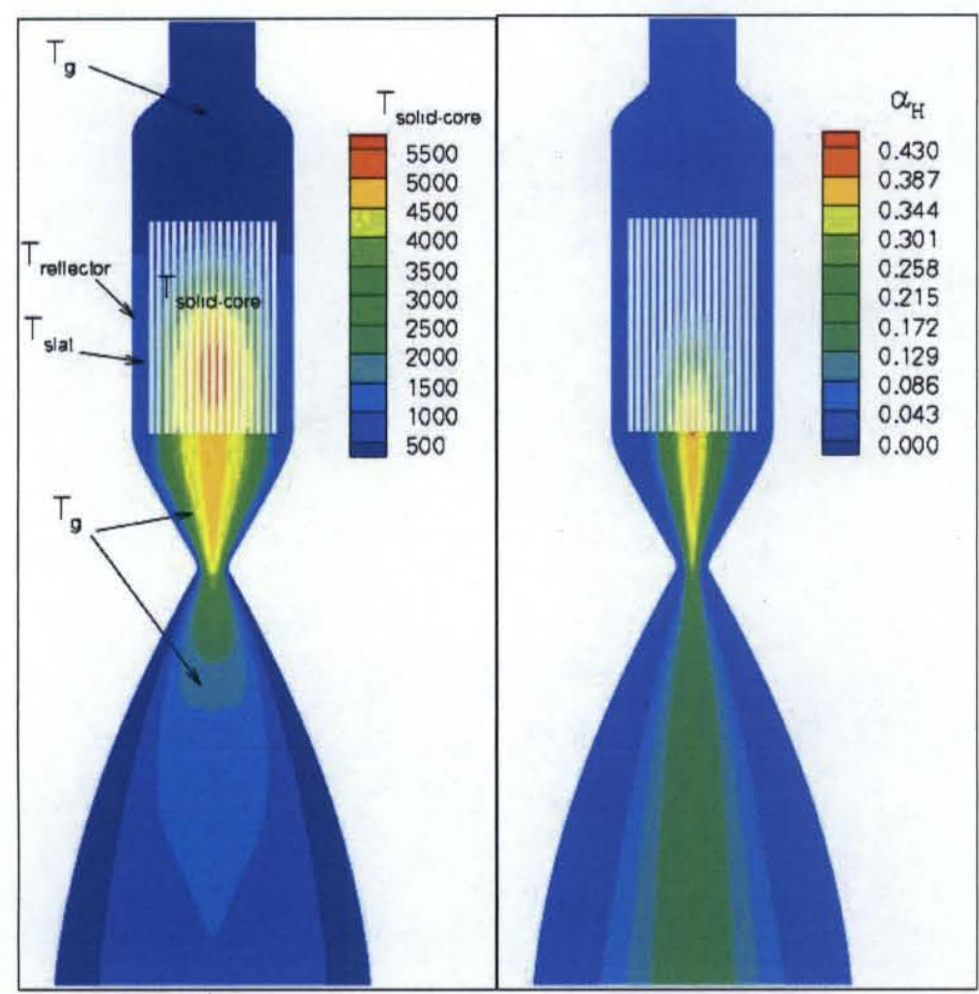

Fig. 5 Solid and gas temperatures, and hydrogen atom mass fraction contours on the symmetry plane for Case 1 . solid-core represent the solid temperatures in the flow elements, the portions surrounding the solid-core depict the temperatures in the slat and reflector, while the rest are the gas temperature contours. It can be seen that the solid-core temperature contours reflect the Cosine-Cosine power distribution with a heat transfer delay in the axial direction. The hydrogen gas temperature contours in the solid core (not shown) take the same shape as those of the solid temperature, except lower. The heat transfer delay in the axial direction is a result of the energy balance between the cooling from the incoming cold hydrogen in the flow channels and the heating from the nuclear material in the web of the flow elements. It is apparent that the effect of cold hydrogen pushes the peak flow element temperature downstream. The hydrogen atom contours also look similar to those of the solid-core temperature contours, with the peak conversion pushed to near the end of the core due to the same reason that pushed the peak solid temperature away from the center core. Coolant hydrogen enters the thrust chamber at about $370 \mathrm{deg}$. $\mathrm{K}$, heats up to about $4800 \mathrm{deg}$. $\mathrm{K}$ in the solid-core, then cools and expands into the diverging nozzle to generate the thrust. Molecular hydrogen decomposes to atomic hydrogen at about $2400 \mathrm{deg}$. K, hence most of the hydrogen atoms are formed while in the flow elements. Once the local temperature starts to cool, i.e., during the expansion in the nozzle, hydrogen atoms recombine to become molecular hydrogen. The peak hydrogen atom mass fraction in Case 1 is 0.40 , or $40 \%$ conversion.

Figure 6 shows the computed solid and gas axial temperature profiles on the symmetry plane, mostly in the solid-core. Only the temperature profiles for the $1^{\text {st }}, 3^{\text {rd }}, 5^{\text {th }}, 7^{\text {th }}$, and $9^{\text {th }}$ flow element from the center tie-tube are plotted for clarity. The solid temperatures lead those of the gas temperatures, showing the effect of the heat transfer coefficient between the flow element and gas. The gas temperatures appear to peak near the core exit, while the solid temperatures appear to peak earlier for the $1^{\text {st }}, 3^{\text {rd }}$, and $5^{\text {th }}$ fuel element, but not for the $7^{\text {th }}$ and $9^{\text {th }}$ fuel element. The lead decreases at the $7^{\text {th }}$ flow element, and disappears completely at the $9^{\text {th }}$ flow element. These axial temperature profiles reflect the effect of the Cosine-Cosine power profile that concentrates the power in the middle of the core, and drops to zero at the core boundary. The peak solid temperature for the $9^{\text {th }}$ flow element is the lowest at around $700 \mathrm{deg} . \mathrm{K}$. The gas core-exit temperature is about $4600 \mathrm{deg} . \mathrm{K}$ at the $1^{\text {st }}$ flow element, and again about $700 \mathrm{deg} . \mathrm{k}$ at the $9^{\text {th }}$ flow element. The 3900 deg. $\mathrm{K}$ temperature spread indicates a very non-uniform temperature distribution at the core-exit, or poor heat transfer efficiency, caused by the Cosine-Cosine power distribution. Note the temperature gradient of the solid temperature is very steep for the $1^{\text {st }}$ flow element occurring at a location between the core entrance and the peak temperature, indicating the mid-section corrosion could have happened over here. 


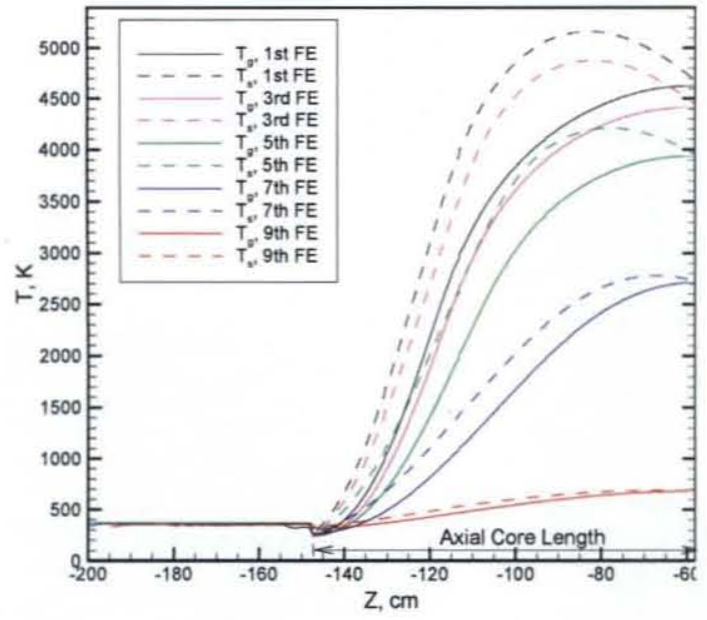

Fig. 6 Solid and gas axial temperature profiles for the $1^{\text {st }}, 3^{\text {rd }}, 5^{\text {th }}, 7^{\text {th }}$, and $9^{\text {th }}$ flow elements on the symmetry plane for Case 1 .

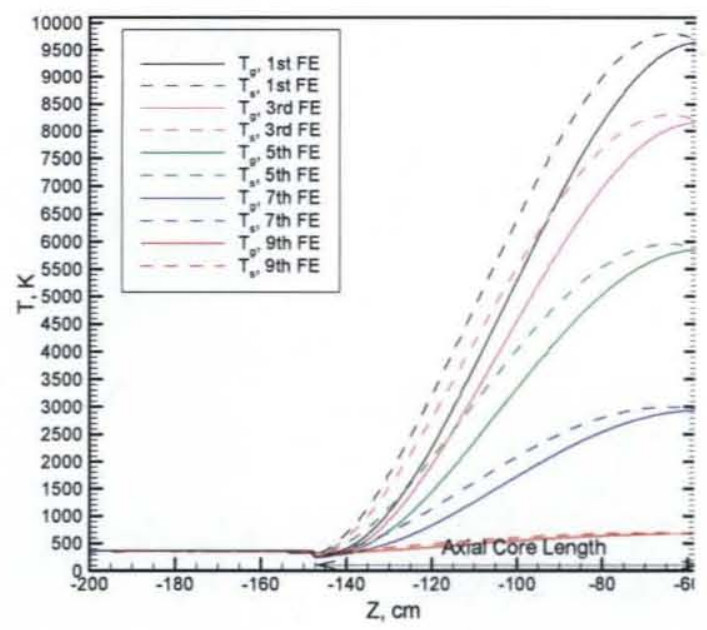

Fig. 7 Solid and gas axial temperature profiles for the $1^{\text {st }}, 3^{\text {rd }}, 5^{\text {th }}, 7^{\text {th }}$, and $9^{\text {th }}$ flow elements on the symmetry plane for Case 2 .

\section{Case 2: Cosine-Cosine power profile, frozen chemistry}

Frozen chemistry means the entering coolant hydrogen composition is frozen and that the molecular hydrogen decomposition is not allowed and hydrogen atom is not formed. As a result, the temperatures of the frozen chemistry case are much higher than those of the finite-rate chemistry case. This is because the hydrogen decomposition reaction is endothermic. That is, a lot of heat was used to decompose molecular hydrogen into the atomic hydrogen in the finite-rate chemistry case. The frozen chemistry case is obviously theoretical and its high solid and gas temperatures are not physical, since hydrogen decomposition occurs naturally. The frozen chemistry case though, demonstrates that the inclusion of finite-rate chemistry calculation is important in getting the proper energy balance and hence the correct temperature predictions.

Figure 7 shows the computed solid and gas axial temperature profiles for the $1^{\text {st }}, 3^{\text {rd }}, 5^{\text {th }}, 7^{\text {th }}$, and $9^{\text {th }}$ flow elements on the symmetry plane, for the CosineCosine power distribution with frozen

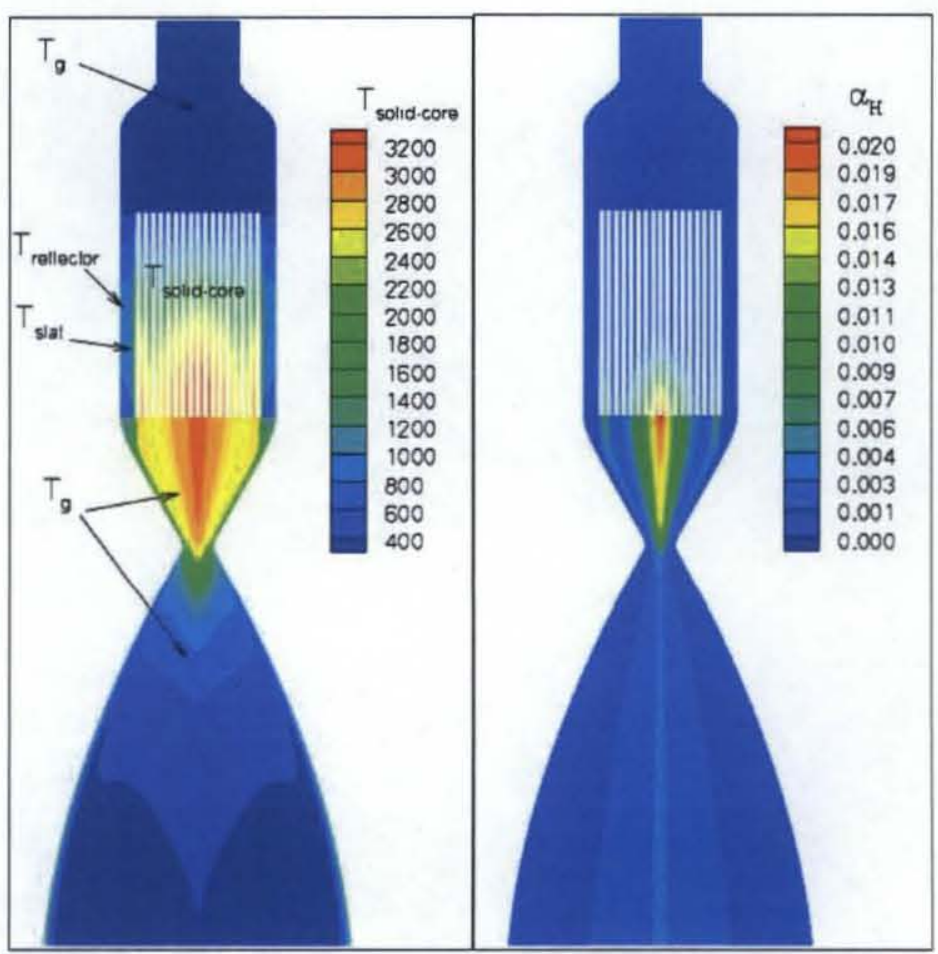

Fig. 8 Solid and gas temperatures, and hydrogen atom mass fraction contours on the symmetry plane for Case 3 . chemistry case. The peak core-exit gas temperature at the first flow element is about $9400 \mathrm{deg}$. $\mathrm{K}$, while that for the $9^{\text {th }}$ flow element is about $650 \mathrm{deg}$. $\mathrm{K}$. The gas temperature spread at the core-exit is therefore about $8750 \mathrm{deg}$. K, much bigger than the $3900 \mathrm{deg}$. $\mathrm{K}$ of the 
finite-rate chemistry case. This is again not physical since hydrogen decomposition occurs naturally whenever the gas temperature exceeds $2400 \mathrm{deg}$. K.

\section{Case 3: Clipped Cosine-flattened power profile, finite-rate chemistry}

It is obvious that the Cosine-Cosine power distribution not only causes peak solid temperatures that are too high, but also the very non-uniform core-exit gas temperatures, indicating inefficient heat transfer. Fortunately, by varying the Uranium loading, a flattened distribution in the radial direction could be achieved, as shown in Fig. 4. Note that this profile is not completely flat, since the normalized power is at about 1.1 in the middle, drops to a minimum at about 0.9 , rising to a maximum of 1.6 at the boundary. But relative to the nominal Cosine power profile, it is relatively flat. Figure 8 shows the computed solid and gas temperatures, and hydrogen atom mass fraction contours for the clipped Cosine-flattened power profile with finite-rate chemistry case. It can be seen that the solid and gas temperature contours and the atomic hydrogen contours, reflect the effect of the clipped Cosine-flattened power distribution shown in Figs. 3 and 4. Comparing to the temperature contours in Fig. 5, those in Fig. 8 are more uniform. The peak solid and gas temperatures in Fig. 8 at about 3149 and 3081 deg. K., respectively, are much lower than those in Fig. 5, or 5369 and 4596 deg. K., respectively. As a result, the peak hydrogen atom mass fraction also drops from a high 0.40 in Fig. 5 to a low 0.02 , or a $2 \%$ conversion. Note that the atomic hydrogen contours exhibit a more pronounced striation in the pressure vessel beneath the core than those in Case 1 . This is caused by the higher power profile at the core boundary, resulting in higher temperature at the boundary which promotes more local hydrogen conversion than that of Case 1.

Figure 9 shows the computed solid and gas axial temperature profiles on the symmetry plane. Comparing to those in Fig. 6, it can be seen that other than the $9^{\text {th }}$ element, the solid temperature in general only leads the gas temperature slightly. This is because of this flattened radial power profile is more uniform than the nominal Cosine profile used for Fig. 6. The peak core-exit gas temperature at the $1^{\text {st }}$ fuel element is about $3037 \mathrm{deg}$. K., while that at the $9^{\text {th }}$ fuel element is about $2514 \mathrm{deg}$. K. The temperature spread of the gas temperature at the core-exit is hence

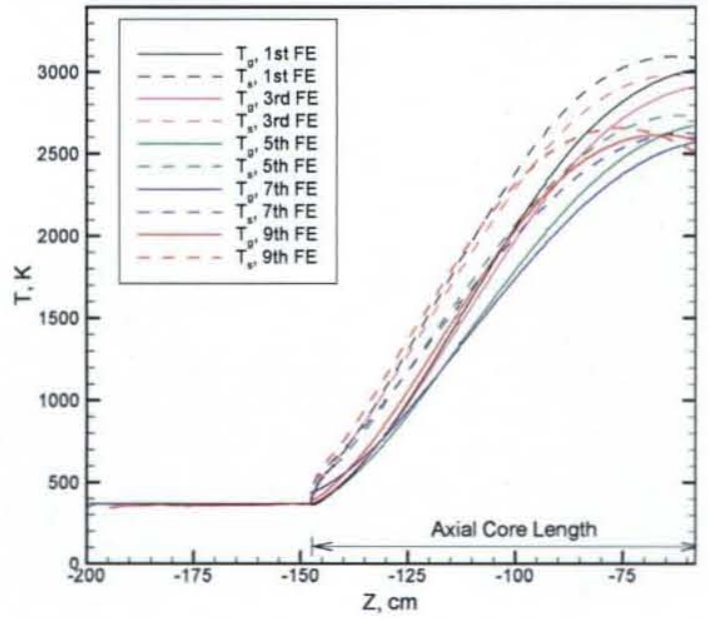

Fig. 9 Solid and gas axial temperature profiles for the $1^{\text {st }}, 3^{\text {rd }}, 5^{\text {th }}, 7^{\text {th }}$, and $9^{\text {th }}$ flow elements on the symmetry plane for Case 3 .

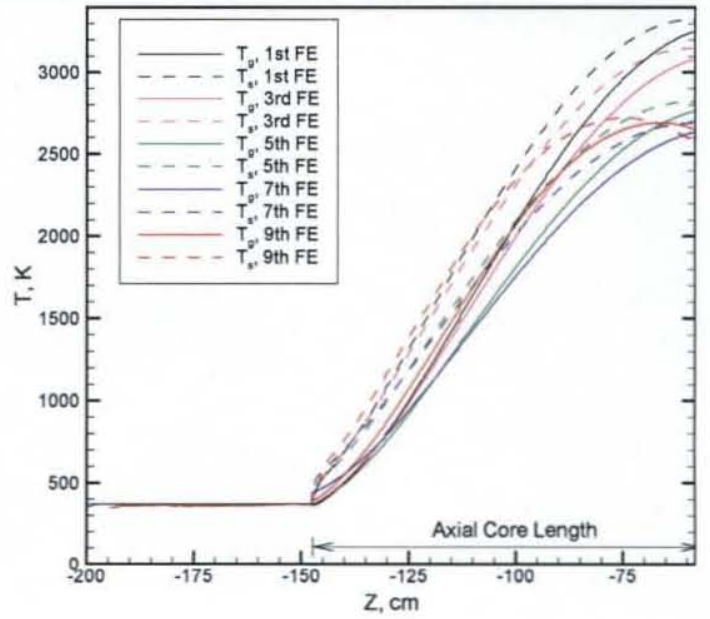

Fig. 10 Solid and gas axial temperature profiles for the $1^{\text {st }}, 3^{\text {rd }}, 5^{\text {th }}, 7^{\text {th }}$, and $9^{\text {th }}$ flow elements on the symmetry plane for Case 4 .

only about $523 \mathrm{deg}$. $\mathrm{K}$, much less than that of $3900 \mathrm{deg} . \mathrm{k}$ in Case 1, indicating the gas core-exit temperature of Case 3 is much more uniform than that of Case 1 . The flattened radial power profile is therefore an improvement over the Cosine power distribution.

Note that it is possible to physically flatten the flattened radial power profile of Fig. 4 even more, with further fine tuning of the Uranium loading. In addition, the hydrogen mass flow may be profiled similar to the radial power profile. That way, the mass flow rates at locations of higher power will be high, while those at locations of lower power will be low. The result is an even more uniform core-exit gas temperature distribution than that in Case 3 . The mass flow profiling may be physically achieved with the installation of various sizes of orifices at the entrance 
of each flow element. The effect of mass flow profiling may also be numerically modeled with the current modeling technique, but out of the scope of this task.

\section{Case 4: Clipped Cosine-flattened power profile, frozen chemistry}

Fig. 10 shows the computed solid and gas axial temperature profiles on the symmetry plane for Case 4. The depictions for the temperature profiles in Fig. 10 are very similar to those of Fig. 9 except the peak temperatures and the temperature spread are slightly higher, due to the frozen chemistry. The reason why the temperature differences between Case 3 and Case 4 are much smaller than those of Case 1 and Case 2 is because of the power distributions. The effect of frozen chemistry is more pronounced with the non-uniform Cosine-Cosine power profile than with the more uniform clipped Cosine-flattened power profile.

\section{Case 5: Clipped Cosine-flat power profile, finite-rate chemistry}

Case 5 uses the clipped Cosine profile for the axial power distribution and a flat profile for the radial power distribution. The resulting temperature and hydrogen mass fraction contours are shown in Fig. 11. It can be seen in terms of the solid-core radial temperature distribution and

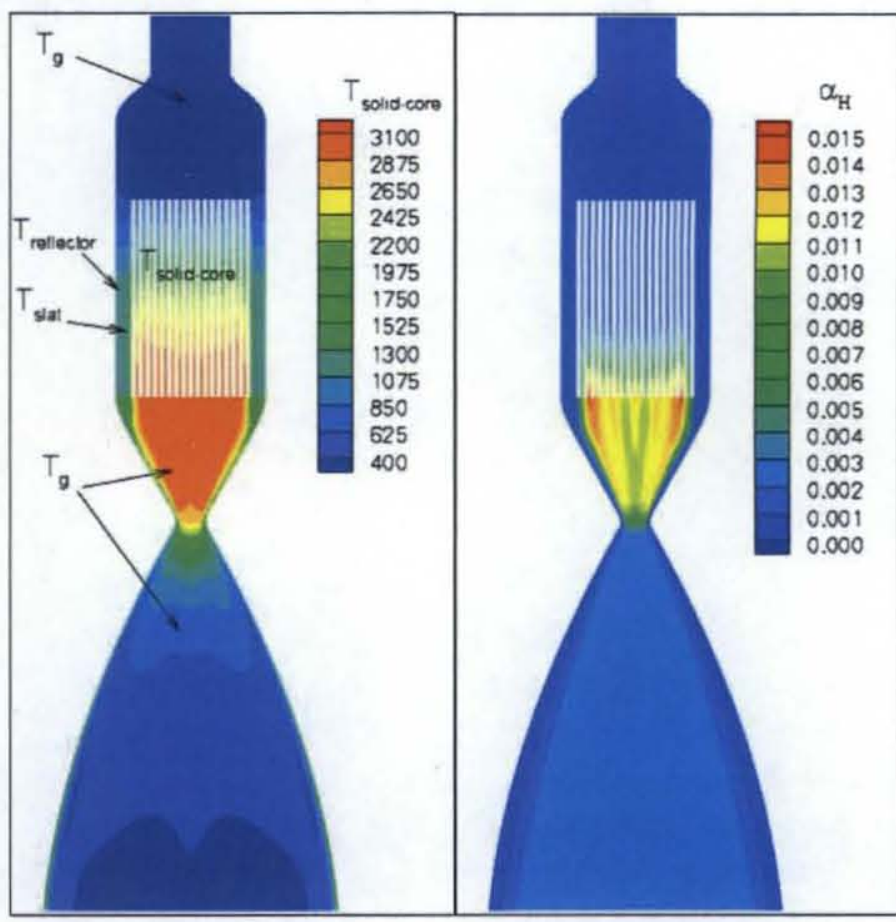

Fig. 11 Solid and gas temperatures, and hydrogen atom mass fraction contours on the symmetry plane for Case 5 . the uniformity of the gas temperature beneath the solid core, this one is the most uniform; so is the hydrogen mass fraction contours. Note that the hydrogen atom conversion is only about $1.5 \%$.

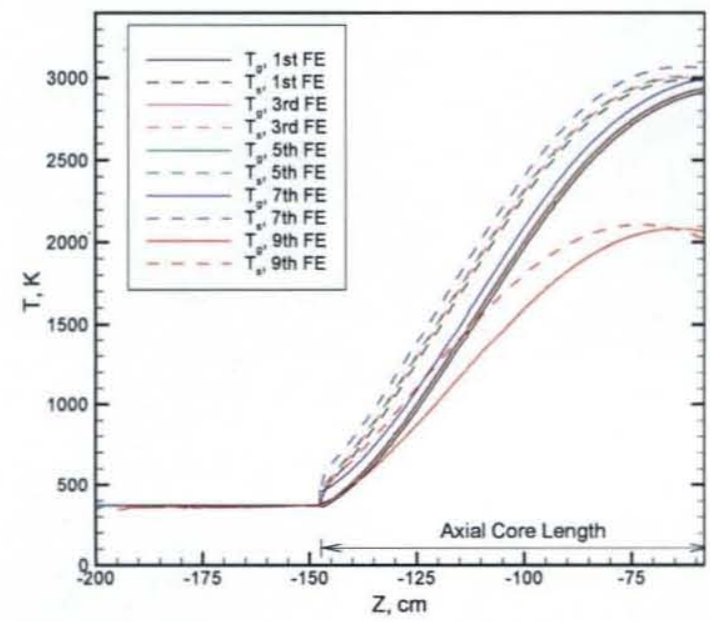

Fig. 12 Solid and gas axial temperature profiles for the $1^{\text {st }}, 3^{\text {rd }}, 5^{\text {th }}, 7^{\text {th }}$, and $9^{\text {th }}$ flow elements on the symmetry plane for Case 5 .
Figure 12 shows the solid and gas axial temperature profiles for the $1^{\text {st }}, 3^{\text {rd }}, 5^{\text {th }}, 7^{\text {th }}$, and $9^{\text {th }}$ flow elements in the solid-core. It can be seen that the temperature spread among the $1^{\text {st }}, 3^{\text {rd }}, 5^{\text {th }}$ and $7^{\text {th }}$ flow elements are much smaller than those of earlier cases, except those of the $9^{\text {th }}$ flow element due to the heat loss to the slat and reflector. From Figs 11 and 12 , it can be seen this flat radial power profile is a very good power profile in terms of general uniformity of the temperatures for both solid and gas temperatures inside the core and for gas exit temperatures.

Table 3 shows a summary of the computed heat transfer and thrust performance parameters. The second column shows the averaged core-exit gas temperatures. These were obtained by averaging the centerline temperatures at the coreexit for all nine elements on the symmetry plane. It can be seen that the averaged core-exit gas temperatures for the Cosine-Cosine power distribution cases are much higher than the Small Engine design temperature of $2750 \mathrm{deg}$. K, while

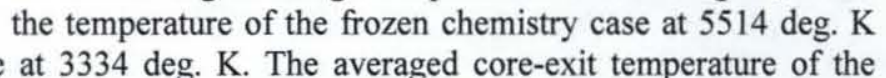
is much higher that of the finite-rate chemistry case at $3334 \mathrm{deg}$. K. The averaged core-exit temperature of the
clipped Cosine-flattened power distribution cases are much lower, with $2785 \mathrm{deg}$. K for the finite-rate chemistry case and $2927 \mathrm{deg}$. K for the frozen chemistry case. As mentioned before, the hydrogen decomposition is endothermic, hence the temperatures of the frozen chemistry case are higher than those of the finite-rate chemistry case. And again since hydrogen decomposition is naturally occurring at high temperatures, the results for the frozen 
chemistry cases are unphysical but demonstrated that the importance of including the finite-rate chemistry calculation for accurate temperature predictions. As for case 5, its averaged core-exit gas temperature at $2782 \mathrm{deg}$. $\mathrm{K}$ is the closest to that of the Small Engine design value.

Table 3 A summary of the heat transfer and performance parameters.

\begin{tabular}{|c|c|c|c|c|c|}
\hline Case & $\mathrm{T}_{\text {g,core exit }} \mathrm{K}$ & $\Delta \mathrm{T}_{\text {g,core exit }} \mathrm{K}$ & $\mathrm{ISP}$ & $\Delta \mathrm{P}_{\text {core, }}, \mathrm{atm}$ & $\mathrm{T}_{\text {s,max }}$ \\
\hline 1 & 3334 & 3900 & 811 & 8.9 & 5369 \\
\hline 2 & 5514 & 8750 & 844 & 8.9 & 9366 \\
\hline 3 & 2785 & 523 & 868 & 9.1 & 3149 \\
\hline 4 & 2927 & 654 & 873 & 9.1 & 3365 \\
\hline 5 & 2782 & 842 & 900 & 9.1 & 3066 \\
\hline Small Engine & 2750 & - & $860 \sim 875$ & 9.0 & \\
\hline
\end{tabular}

The third column shows the temperature spread, or the difference of the core-exit gas temperature between the first and the $9^{\text {th }}$ flow elements. Lower spread represents more uniform temperature distribution amongst the flow elements, or better heat transfer efficiency. It can be seen that the more uniform clipped Cosine-flattened power profile produces better heat transfer efficiency than that of the Cosine-Cosine power distribution. For example, the temperature spread of $523 \mathrm{deg}$. K of Case 3 is much less than that of $3900 \mathrm{deg}$. K of Case 1 . Again, frozen chemistry results in higher spread than that of the finite-rate chemistry. Note although the temperature spread of Case 5 at 842 deg. $\mathrm{K}$ is higher than those of Cases 3 and 4 , it is actually more uniform in most of the core, except at the $9^{\text {th }}$ flow element.

The fourth column shows the computed specific impulses. Remember that the maximum atomic hydrogen mass fraction is 0.4 for case 1, 0.02 for Case 3, and 0.015 for Case 5, yet the ISP of Case 5 is higher than that of Case 3, which in turn is higher than that of case 1 . These results demonstrated that the notion of higher temperature, more atomic hydrogen, therefore higher thrust is not likely true. Rather, based on a fixed power, it is the more uniform power profile that produces the higher thrust. The fifth column shows the comparison of the computed core pressure drops. It can be seen that all are close to the design value of $9 \mathrm{~atm}$, although those of the Cosine-Cosine power distribution are slightly lower. The last column shows the computed peak solid temperatures. It can be seen that the lowest peak solid temperature belongs to the Case 5 and the reason is clear.

The computed averaged core-exit gas temperature, specific impulse, and core pressure drop of Case 3 agree very well with those of the design values, indicating the simulation with the computational model developed in this work, closely simulated the fluid, thermal, and hydrogen environments in the Small Engine design. On the other hand, the computed averaged core-exit gas temperature and core pressure drop are equally good with Case 5, yet its ISP is 32 $\mathrm{s}$ higher than that of the Case 3, demonstrating the more uniform radial power distribution generates higher heat transfer efficiency, lower peak solid temperature, and higher thrust performance.

\section{Conclusion}

A multiphysics, computational heat transfer methodology was developed to predict heat transfer efficiency and thrust performance for a hypothetical solid-core, nuclear thermal engine thrust chamber - the Small Engine. The methodology computes a unified thrust chamber thermal field constituting the inlet plenum, the pressure vessel, and the nozzle. Multiphysics invoked include the turbulent flow and heat transfer, finite-rate chemistry, and conjugate heat transfer. The computed result of the core-exit gas temperature, core pressure drop, and specific impulse for the clipped Cosine-flattened power profile agree with the design very well. Finite-rate chemistry is very important in predicting the proper energy balance as naturally occurring hydrogen decomposition is endothermic. In addition, high hydrogen conversion neither improves the heat transfer efficiency, nor increasing the thrust performance. Rather, it is the more uniform power profile that produces lower peak solid temperature, higher heat transfer efficiency, and higher thrust performance.

\section{Acknowledgments}

This study was partially supported by a Nuclear Systems Office task entitled "Multiphysics Thrust Chamber Modeling" with an earmark funding from the Prometheus Power and Propulsion Office, NASA Headquarter. Wayne Bordelon was the Nuclear Thermal Propulsion manager. Michael Houts was the Nuclear Research Manager. Steve Simpson and Karl Nelson provided the clipped Cosine-flattened power profile, nozzle geometry and system modeling results. Bill Emrich suggested the Cosine power profile. Jeff Lin debugged the porosity drag calculation. 
Solid material thermal properties provided by Panda Binayak, Robert Hickman, and Bill Emrich are also acknowledged.

\section{References}

${ }^{1}$ Bordelon, W.J., Ballard, R.O., and Gerrish, Jr., H.P., "A Programmatic and Engineering Approach to the Development of a Nuclear Thermal Rocket for Space Exploration,” AIAA Paper 2006-5082, July 2006.

${ }^{2}$ Koenig, D.R., "Experience Gained from the Space Nuclear Rocket Program (Rover)," LA-10062-H, Los Alamos National Laboratory, Los Alamos, New Mexico, 1986.

${ }^{3}$ Lyon, L.L., "Performance of (U,Zr)C-Graphite (Composite) and of (U,Zr)C (Carbide) Fuel Elements in the Nuclear Furnace 1 Test Reactor," LA-5398-MS, Los Alamos Scientific Laboratory, Los Alamos, New Mexico, 1973.

${ }^{4}$ Wang, T.-S., Luong, V., Foote, J., Litchford, R., and Chen, Y.-S., "Analysis of a Cylindrical Specimen Heated by an Impinging Hot Hydrogen Jet," AIAA Paper 2006-2926, $9^{\text {th }}$ AIAA/ASME Joint Thermophysics and Heat Transfer Conference, San Francisco, CA, 2006.

5James, E.A., J., "Gas Dynamics", Allyn and Bacon, Inc., Boston, Mass., 1969.

${ }^{6}$ Wang, T.-S., Foote, J., and Litchford, R., "Multiphysics Thermal-Fluid Design Analysis of a Non-Nuclear Tester for Hot-Hydrogen Material Development," Space Technology and Applications International Forum (STAIF-2006), Albuquerque, NM, Fe. 12-16, 2006, American Institute of Physics Proceedings, edited by El-Genk, M.S., Melville, N.Y., Vol. 813, 2006, pp. 537-544.

${ }^{7}$ Durham, F.P., "Nuclear Engine Definition Study", Preliminary Report, Vol. 1 - Engine Description, LA-5044MS, Los Alamos Scientific Laboratory, Los Alamos, New Mexico, September 1972.

${ }^{8}$ Cheng, G., Ito, Y., Ross, D., Chen, Y.-S., and Wang, T.-S., "Numerical Simulations of Single Flow Element in a Nuclear Thermal Thrust Chamber," AIAA Paper 2007-4143, $39^{\text {th }}$ AIAA Thermophysics Conference, Miami, FL, 2007.

${ }^{9}$ Chen, Y.-S., Liu, J., Zhang, S., and Mallapragada, P., "An Integrated Tool for Launch Vehicle Base-Heating Analysis," Final Report, NAS8-00002, Engineering Sciences, Inc., Huntsville, AL, 2001.

${ }^{10}$ Chen. Y.-S., Zhang S., and Liu, J., "Stage Separation Performance Analysis Project," Final Report, H-34345D, Engineering Sciences, Inc., Huntsville, AL, 2002.

${ }^{11}$ Wang, T.-S., Chen, Y.-S., Liu, J., Myrabo, L.N., and Mead, F.B. Jr., "Advanced Performance Modeling of Experimental Laser Lightcraft,” Journal of Propulsion and Power, Vol. 18, No. 6, 2002, pp. 1129-1138.

${ }^{12}$ Wang, T.-S., "Multidimensional Unstructured-Grid Liquid Rocket Engine Nozzle Performance and Heat Transfer Analysis," Journal of Propulsion and Power, Vol. 22, No. 1, 2005, pp. 78-84.

${ }^{13}$ Wang, T.-S., "Transient 3-D Analysis of Nozzle Side Load in Regeneratively Cooled Engines," AIAA Paper 2005-3942, $41^{\text {st }}$ AIAA/ASME/SAE/ASEE Joint Propulsion Conference, Tucson, Arizona, 2005.

${ }^{14}$ Chen, Y.-S., and Kim, S. W., "Computation of Turbulent Flows Using an Extended k- $\varepsilon$ Turbulence Closure Model," NASA CR-179204, 1987.

${ }^{15}$ Bird, R.B., Stewart, W.E., Lightfoot, E.N., "Transport Phenomena," 1960.

${ }^{16}$ Gaski, J., "The Systems Improved Numerical Differencing Analyzer (SINDA) Code - a User's Manual," Aerospace Corp., El Segundo, CA, Feb. 1986.

${ }^{17}$ Wang, T.-S. and Schutzenhofer, L. A., "Numerical Analysis of a Nuclear Fuel Element for Nuclear Thermal Propulsion," AIAA Paper 91-3576, September, 1991.

${ }^{18}$ Cheng, G.-C., Chen, Y.-S., and Wang, T.-S., "Flow Distribution Around the SSME Main Injector Assembly Using Porosity Formulation," AIAA Paper 95-0350, January, 1995.

${ }^{19}$ Steinbrenner, J.P., Chawner, J.R., and Fouts, C., "Multiple Block Grid Generation in the interactive Environment," AIAA Paper 90-1602, June 1990.

${ }^{20}$ McBride, B.J., Zehe, M.J., and Gordon, S., "NASA Glenn Coefficients for Calculating Thermodynamic Properties of Individual Species," NASA TP-2002-211556, Glenn Research Center, Cleveland, Ohio. September, 2002.

${ }^{21}$ Wang, T.-S., "Thermophysics Characterization of Kerosene Combustion," Journal of Thermophysics and Heat Transfer, Vol. 15, No. 2, 2001, pp. 140-147.

${ }^{22}$ Baulch, D.L., Drysdale, D.D., Horne, D.G., and LLoyd, A.C., "Evaluated Kinetic Data for High temperature Reactions", Vol. 1, The Chemical Rubber Company, Cleveland, Ohio, 1972.

${ }^{23}$ Glasstone, S., and Edlund, M.C., "The Elements of Nuclear Reactor Theory," D. Van Nostrand Company, Inc., Tornoto, Canada, 1958. 


\title{
AIAA 2007-4144
}

\section{Multiphysics Computational Analysis of a Solid-Core Nuclear Thermal Engine Thrust Chamber}

\author{
Ten-See Wang, Francisco Canabal \\ NASA Marshall Space Flight Center, Huntsville, AL 35812 \\ Gary Cheng \\ University of Alabama, Birmingham, AL 35294 \\ and \\ Yen-Sen Chen \\ Engineering Sciences, Inc., Huntsville, AL 35815
}

$3^{\text {th }}$ AIAA Thermophysics Conference

Miami, Florida, June 25-28, 2007 


\section{Acknowledgments}

- This study was partially supported by a Nuclear Systems Office task \#14 entitled "Multi-physics Thrust Chamber Modeling".

- Wayne Bordelon was the Nuclear Thermal Propulsion manager.

- Steve Simpson and Karl Nelson provided nozzle geometry and operating conditions for the hypothetical nuclear thermal engine.

- Bill Emrich suggested the nominal Cosine power profiles. Steve Simpson provided the Clipped Cosine axial power profile and the flattened radial power profile.

- Panda Binayak, Robert Hickman, and Bill Emrich provided thermal properties for solids. 


\section{Introduction}

- Nuclear thermal propulsion can carry larger payloads and reduce travel time to Mars than is now possible with chemical propulsion.

- Solid-core concept was extensively tested during the Rover/NERVA era and appears to be the most feasible.

- This concept involves a solid-core reactor consisting of hundred of heat generating flow elements, and each flow elements containing tens of flow channels through which the working fluid hydrogen acquires energy and expands in a high expansion nozzle to generate thrust.

- The solid-core reactor is a heat exchanger.

- The reactor often operates at very high temperature and power density, which imposes real challenges to the integrity of the flow element material.

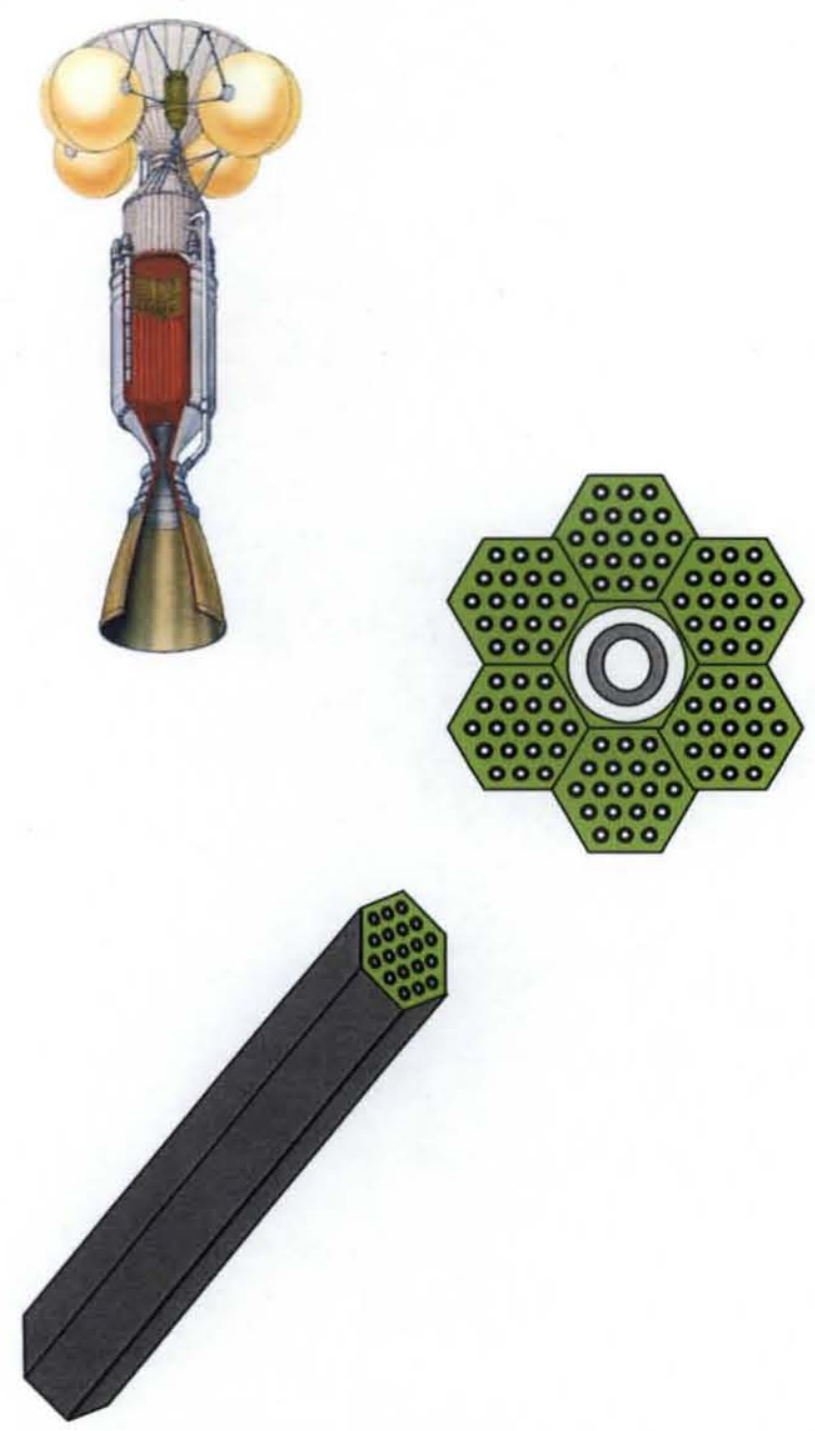




\section{Introduction - continued}

- Effect of hydrogen as a working fluid

- Hydrogen is an excellent propellant

$-\mathrm{H}_{2}=2 \mathrm{H}$

- Effect of hydrogen dissociation in core on heat transfer efficiency?

- Hydrogen atom is a better propellant?

- Effect of hydrogen recombination in nozzle on thrust performance?

- Effect of hydrogen on flow element material

- Hydrogen corrodes away channel walls and protective coatings made of certain materials

- Corrosion enhances with higher temperature

- Penetrates into fuel matrix core and weakens core

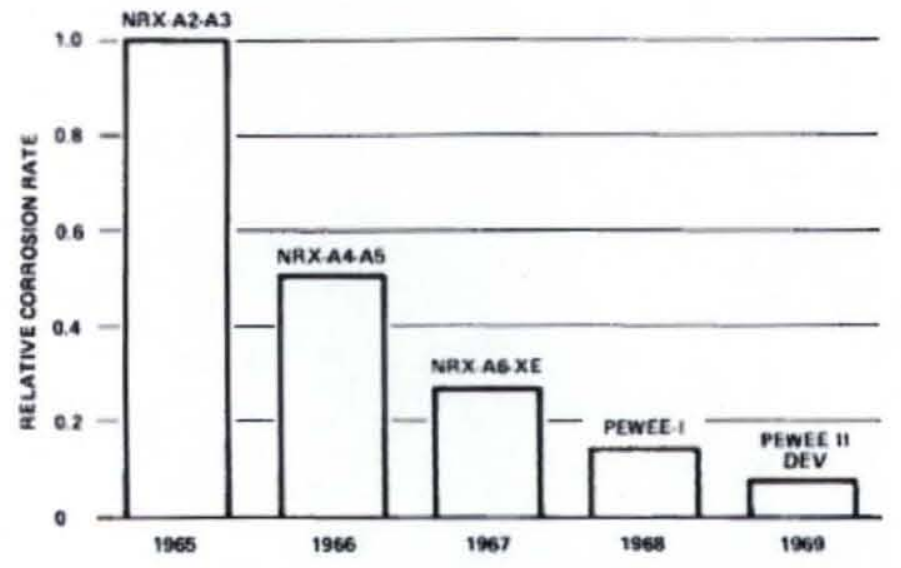




\section{Introduction - continued}

- Mid-section corrosion - cracked coating and excessive mass loss

- Causes of mid-section corrosion:

- Mismatch in the thermal expansion of flow element and its coating material

- Temperature difference between fuel and coating

- High flow element web internal temperature gradients, especially near the coating layer

- Change of solid thermal property due to irradiation

- Side load caused by flow choking in channels

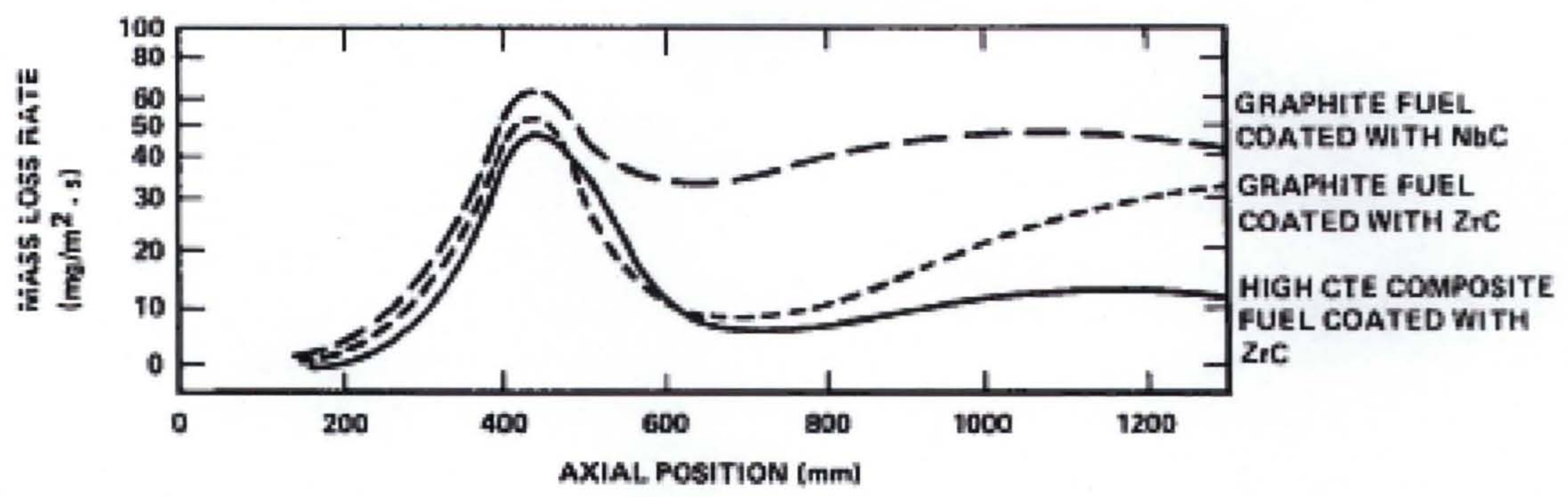




\section{Introduction - continued}

- To make solid-core nuclear thermal rocket a viable concept for Mars missions, we must

- Understand the effects of hydrogen as a working fluid on heat transfer efficiency in core and thrust performance in the nozzle

- Develop materials that withstand the harsh reactor environment

- One way to help understanding the effect of hydrogen as a working fluid and developing materials that withstand the harsh environment is to develop a computational methodology that can accurately predict thermal-fluid environments inside the thrust chamber and reproduce the flow element thermal environment occurring in the legacy engine tests. 


\section{Introduction - continued}

- The objective is to develop an efficient and accurate multiphysics thermo-fluid computational methodology to predict environments for a hypothetical solid-core thrust chamber and the associated flow element, similar to those in the Small Engine.

- The computational methodology was based on an existing CFD code (UNIC). Conjugate heat transfer formulations for coupling fluid dynamics and conductive heat transfer in solids and in porous media were developed and tested.

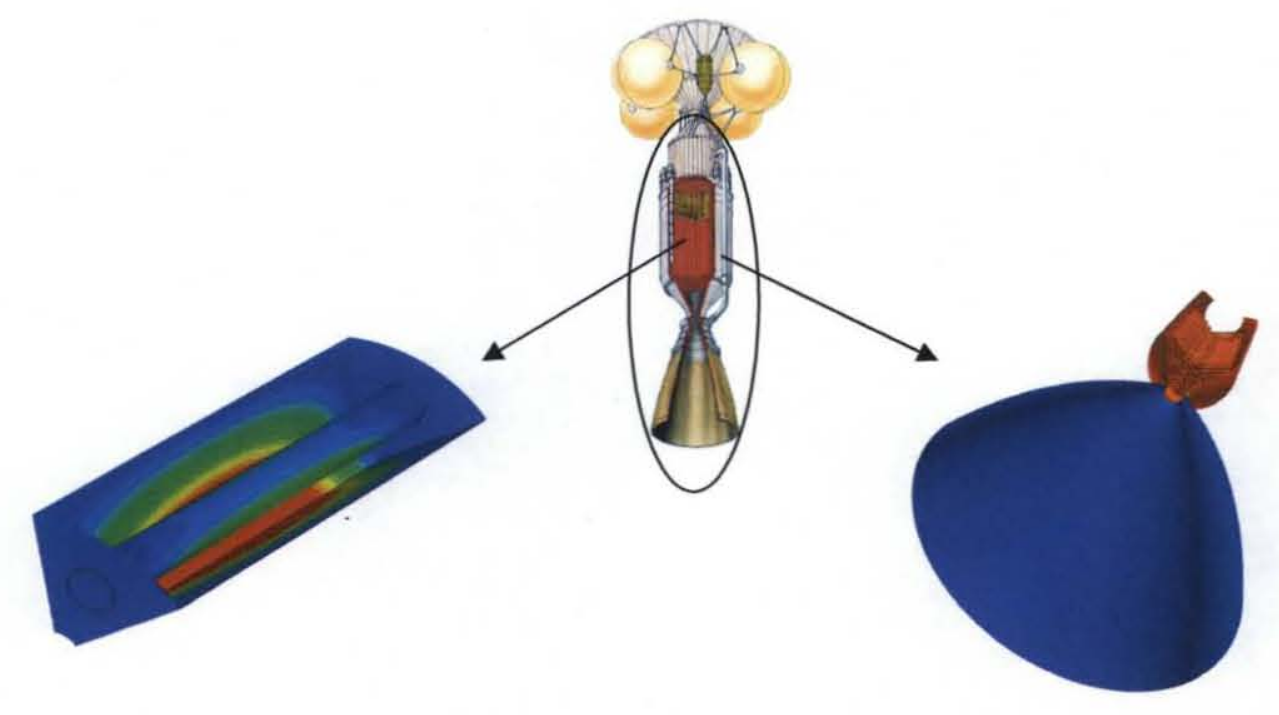




\section{Introduction - continued}

- The physics to be implemented into UNIC:

- Conjugate heat transfer for flow and porous media (global multi-element thrust chamber)

- is being anchored with computational analysis using a 19-channel single flow element configuration

- Conjugate heat transfer for flow and solids (detailed multi-channel flow element)

- Conjugate heat transfer with cylindrical specimen heated by impinging hot-hydrogen jet

- Anchored with standard conductive heat transfer code SINDA.

- Will be further anchored with test data obtained from IR\&D Focus Area Project "Hot Hydrogen Materials and Component Development".

- Conjugate heat transfer with prescribed power distribution

- Will be further anchored with test data obtained from Task \#12 - NTREES
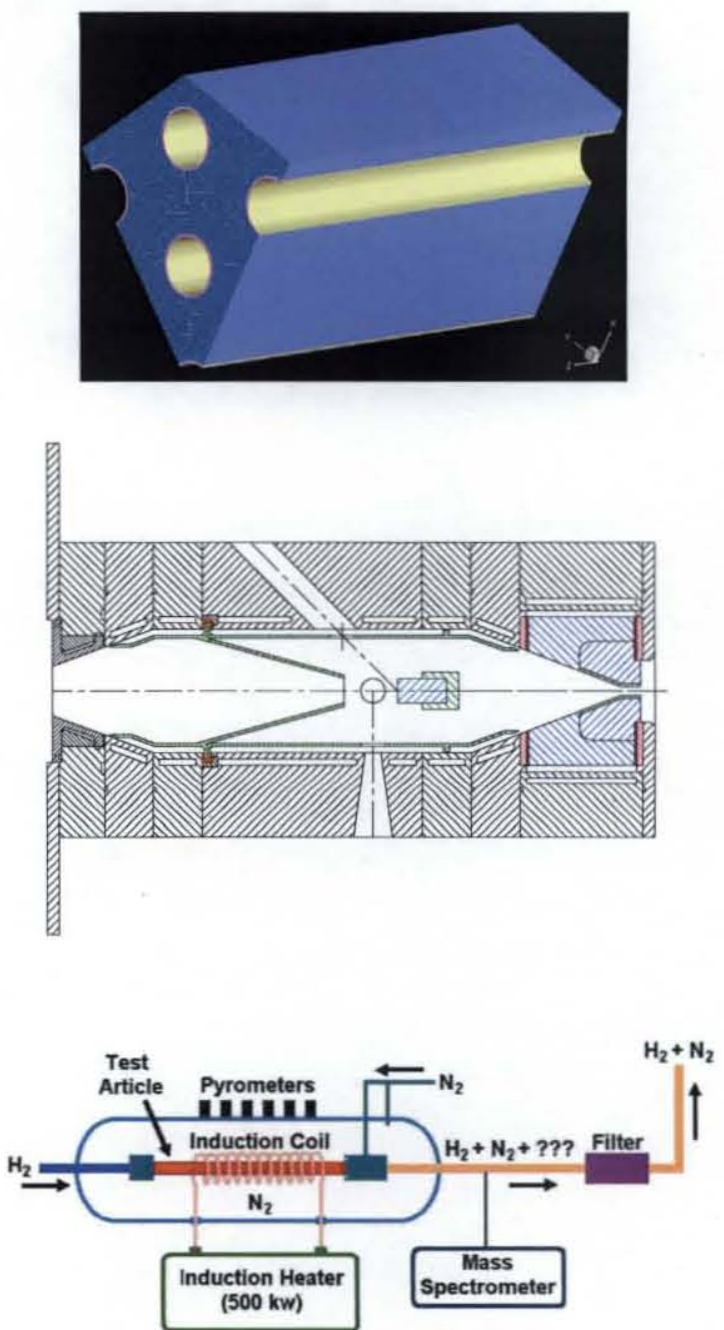
$\frac{\partial \rho}{\partial t}+\frac{\partial}{\partial x_{j}}\left(\rho u_{j}\right)=0$

$\frac{\partial \rho \alpha_{i}}{\partial t}+\frac{\partial}{\partial x_{j}}\left(\rho u_{j} \alpha_{j}\right)=\frac{\partial}{\partial x_{j}}\left[\left(\rho D+\frac{\mu_{t}}{\sigma_{\alpha}}\right)\right]+\omega_{i}$

$\frac{\partial \rho u_{i}}{\partial t}+\frac{\partial}{\partial x_{j}}\left(\rho u_{j} u_{i}\right)=-\frac{\partial p}{\partial x_{i}}+\frac{\partial \tau_{i j}}{\partial x_{j}}$

$\frac{\partial \rho H}{\partial t}+\frac{\partial}{\partial x_{j}}\left(\rho u_{j} H\right)=\frac{\partial p}{\partial t}+Q_{r}+\frac{\partial}{\partial x_{j}}\left[\left(\frac{K}{C_{p}}+\frac{\mu_{t}}{\sigma_{H}}\right) \nabla H\right]+\frac{\partial}{\partial x_{j}}\left\{\left[\left(\mu+\mu_{t}\right)-\left(\frac{K}{C_{p}}+\frac{\mu_{t}}{\sigma_{H}}\right)\right] \nabla\left(\frac{V^{2}}{2}\right)\right\}+\theta$

$\frac{\partial \rho k}{\partial t}+\frac{\partial}{\partial x_{j}}\left(\rho u_{j} k\right)=\frac{\partial}{\partial x_{j}}\left[\left(\mu+\frac{\mu_{t}}{\sigma_{k}}\right) \frac{\partial k}{\partial x_{j}}\right]+\rho(\Pi-\varepsilon)$

$\frac{\partial \rho \varepsilon}{\partial t}+\frac{\partial}{\partial x_{j}}\left(\rho u_{j} \varepsilon\right)=\frac{\partial}{\partial x_{j}}\left[\left(\mu+\frac{\mu_{t}}{\sigma_{\varepsilon}}\right) \frac{\partial \varepsilon}{\partial x_{j}}\right]+\rho \frac{\varepsilon}{k}\left(C_{1} \Pi-C_{2} \varepsilon+C_{3} \frac{\Pi^{2}}{\varepsilon}\right)$ 


\section{Gas-side Governing Equations - Continued}

$$
\begin{aligned}
& u^{+}=\ln \left[\left(y^{+}+11\right)^{4.02} /\left(y^{+^{2}}-7.37 y^{+}+83.3\right)^{0.79}\right]+5.63 \tan ^{-1}\left(0.12 y^{+}-0.441\right)-3.81 \\
& T^{+}=u^{+}+12.8\left(\operatorname{Pr}_{l}^{0.68}-1\right) \\
& Q_{c w}=\left(\rho u_{\tau} / T^{+}\right)\left[h_{w}-h_{p}-R\left(u_{p}^{2} / 2\right)\right]
\end{aligned}
$$


Heat transfer in Solids

$\frac{\partial \rho_{s} C_{p s} T_{s}}{\partial t}-\frac{\partial}{\partial x_{j}}\left(K_{s} \frac{\partial T_{s}}{\partial x_{i}}\right)=Q_{v}+Q_{s}$

Gas / Solid Interface

$\frac{1}{2} \rho C_{p} \frac{T_{0}^{\prime}-T_{0}}{\Delta t}=\frac{1}{\Delta x_{j}}\left(K \frac{T_{1}-T_{0}}{\Delta x_{j}}-Q_{s}\right)$ 


\section{Conjugate Heat Transfer: Flow and Heat Transfer} in Porous Media

Gas - Side Navier - Stokes and Energy Equations in Porous Media

$$
\begin{aligned}
& \frac{\partial \rho u_{i}}{\partial t}+\frac{\partial}{\partial x_{j}}\left(\rho u_{j} u_{i}\right)=-\frac{\partial p}{\partial x_{i}}+\frac{\partial \tau_{i j}}{\partial x_{j}}-\frac{L}{\beta} \\
& \frac{\partial \rho H}{\partial t}+\frac{\partial}{\partial x_{j}}\left(\rho u_{j} H\right)=\frac{\partial p}{\partial t}+Q_{r}+\frac{\partial}{\partial x_{j}}\left[\left(\frac{K}{C_{p}}+\frac{\mu_{t}}{\sigma_{H}}\right) \nabla H\right]+\frac{\partial}{\partial x_{j}}\left\{\left[\left(\mu+\mu_{t}\right)-\left(\frac{K}{C_{p}}+\frac{\mu_{t}}{\sigma_{H}}\right)\right] \nabla\left(\frac{V^{2}}{2}\right)\right\}+\theta+\frac{Q_{s}}{\beta}
\end{aligned}
$$

Solid Heat Conductionin Porous Media

$$
\frac{\partial \rho_{s} C_{p s} T_{s}}{\partial T}-\frac{\partial}{\partial x_{j}}\left(K_{s} \frac{\partial T_{s}}{\partial x_{i}}\right)=\frac{Q_{v}+Q_{s}}{1-\beta}
$$




\section{Multiphysics Analysis}

- Turbulent heat transfer

- Conjugate heat transfer

- Gas and solid

- Gas, solid, porous media

- Power generation

- Variable gas and solid thermodynamic properties

- Finite-rate chemistry 


\section{Finite-Rate Chemistry}

Table 1 Hydrogen reaction kinetics mechanism

\begin{tabular}{|c|c|c|c|c|c|}
\hline Reaction $^{\mathrm{a}}$ & $\mathrm{A}$ & $\mathrm{B}$ & $\mathrm{E} / \mathrm{R}$ & $\mathrm{M}$ & Ref. \\
\hline $\mathrm{M}+\mathrm{H}+\mathrm{H}=\mathrm{H}_{2}+\mathrm{M}$ & $5.0 \mathrm{E} 15$ & 0 & 0 & $\mathrm{H}_{2}, \mathrm{H}$ & 20 \\
\hline $\mathrm{M}+\mathrm{H}_{2} \rightarrow \mathrm{H}+\mathrm{H}+\mathrm{M}$ & $8.8 \mathrm{E} 14$ & 0 & 48300 & $\mathrm{H}_{2}$ & 21 \\
\hline
\end{tabular}

${ }^{\mathrm{a}} \mathrm{M}$ is third-body collision partner and rate constant $\mathrm{K}=\mathrm{AT}^{\mathrm{B}} \exp (-\mathrm{E} / \mathrm{RT})$. 


\section{Detailed Flow Element Model}

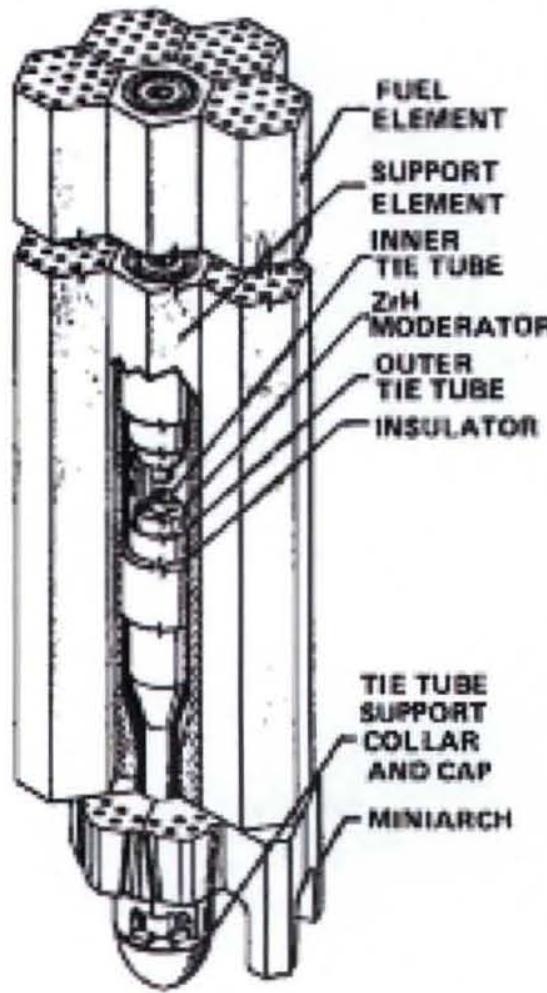

FUEL

\section{FUNCTION}

- PROVIDED ENERGY FOR HEATING HYOACGEN PACOELLANT

- PAOVIDED MEAT TRANSFER SUAFACE

- descaiptica

- ZMU IN A COMPOSITE MATAIX OF UC ZZC SOLID SOLUTION AND $\mathrm{C}$

- CHANNELS CDATED WITH ZTE TO PIOTECT AGAINST $\mathrm{H}_{2}$ REACTIONS

TIE TUBES

\section{- FUNCTION}

- TRANSMIT COAE AXLAL PAESSUIE LOAD FAOM THE HOT END OF THE FUEL ELEMENTS TO THE CORE SUPPQAT PLATE

- ENEREY SOURCE FOR TUABOPUMP

- CONTAIN AND COOL ZUC MODERATOR SLEEVES

- descaiption

- COUNTER FLOW HEAT EXCHANGER OF INCONEL 718

- ZnH MODERATOR

- ZrC INSULATION SLEEVES

Fig. 41. Descriptfon of the Snall Engine fuel nodule design showing the Zril sleeve in the regeneratively cooled tie-tube support elenent.
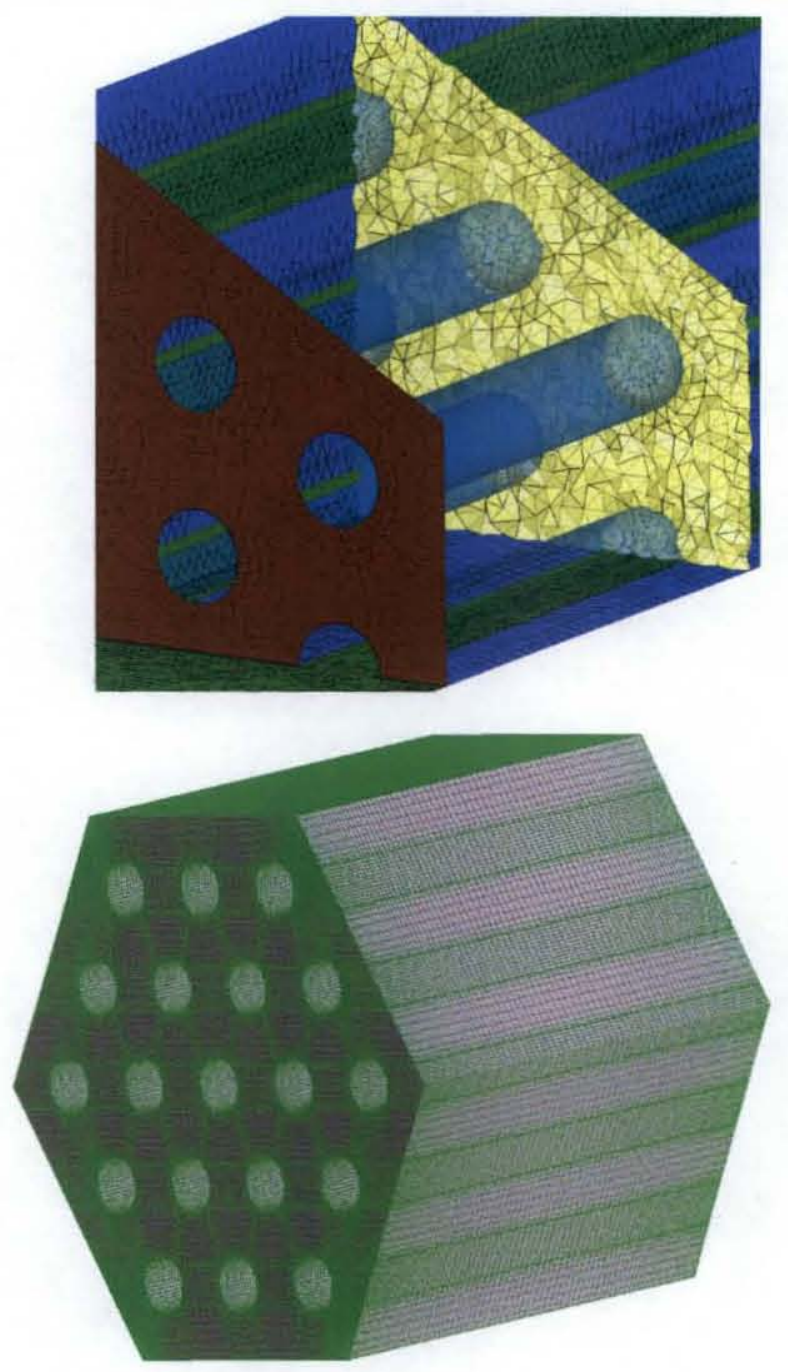

Small Engine Flow Element Bundle 19-channel Flow Element Model 


\section{Global Thrust Chamber Model}

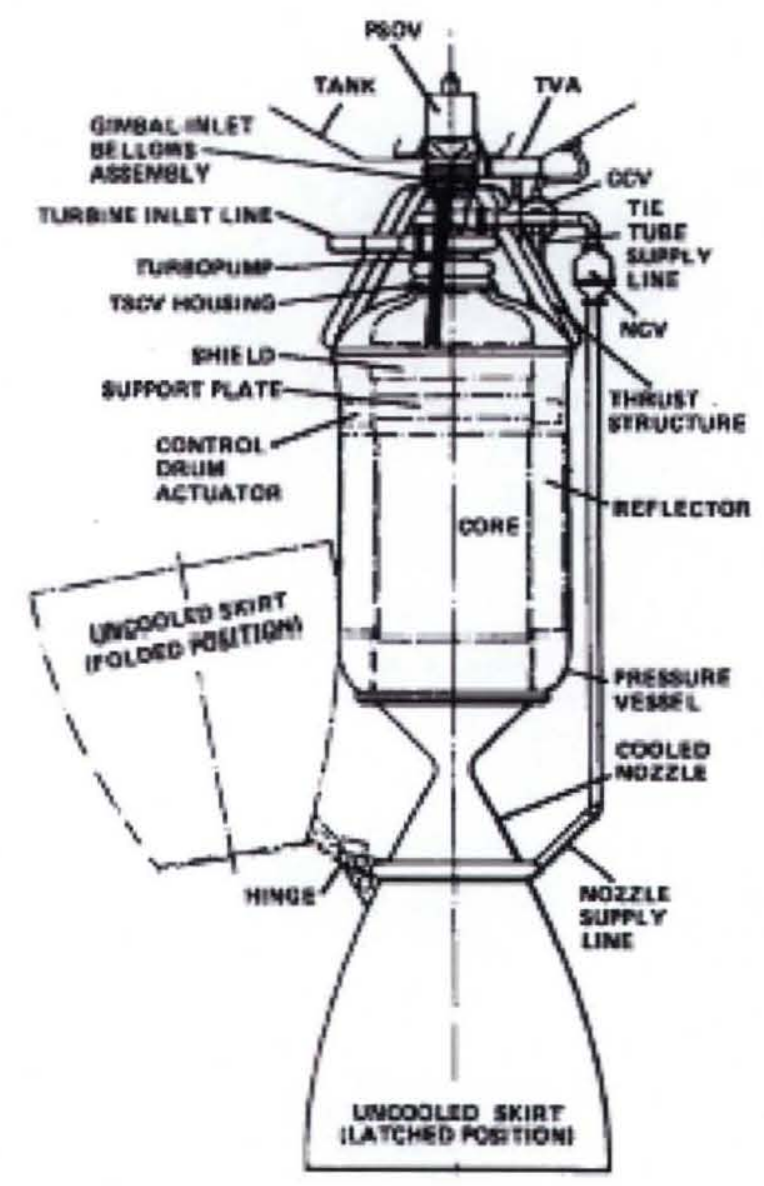

Small Engine

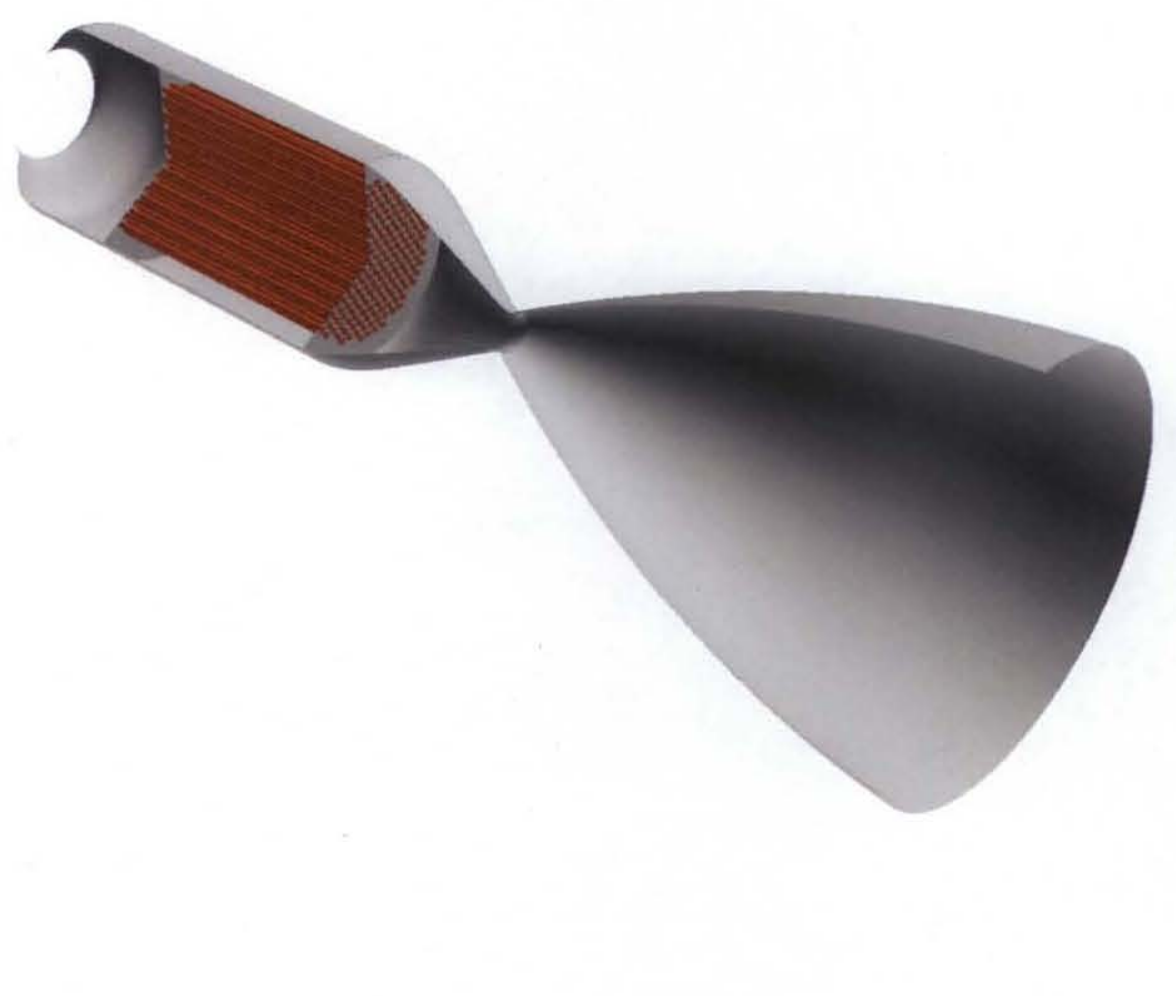

Thrust Chamber Model 


\section{Global Thrust Chamber Model}

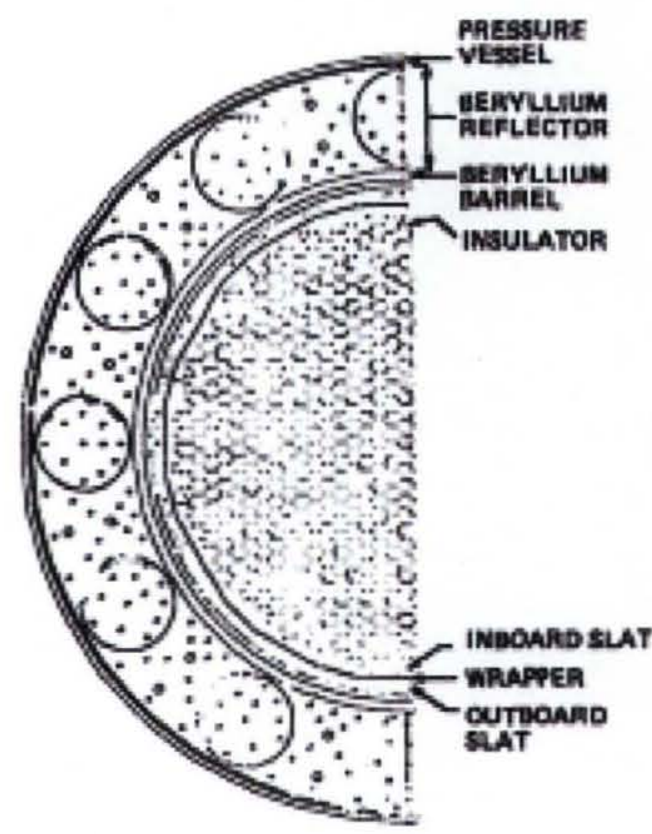

Ppooucts 36s MT

9SE MEXMCOLALLY SHAPED WC-ZICI C COMHOSITE FUEL ELENENTS

- AS1 SUPPOHT ELEMENTS CONTANMING

ZrH NEUTRON MCOERATOR

\section{-19 CoOLANT CHANNELS PER ELTWENT}

ECORE PERIFHERY CONTANS AN OUTER INSULATION LAYER, A COOLEO INBOARO GLAT SECTION, A METAL WHAMER, A COOLED OUTBOARD SLAT SECTION, AND AN TXPANS SON GAP

GAEFLECTON IS BEnYLLILM BARBEL WITH 12 REACNVITY cOWTAOL. DRUMS

- CORE SUPPOAT ON COLD END BY MM ALLMINUM -ALLOY PLATE. BLPPORT PLATE RESTS ON REFLECTOR SYSTEM

DREACTOG FNCLOSED IN ALUMHUM PAESUUAS VESSEL

- caragar of a kn temogatuae tRansients

F1g. 40. Cross-sectlonat description of the Snall Engine concept. The overal1 reactor diaxeter was $950 \mathrm{~m}$. The design used $\mathbf{7 n + 1 - t o d e r}$ ted support elenents, as was done in Pewee, to reduce the uranfun critical nass.
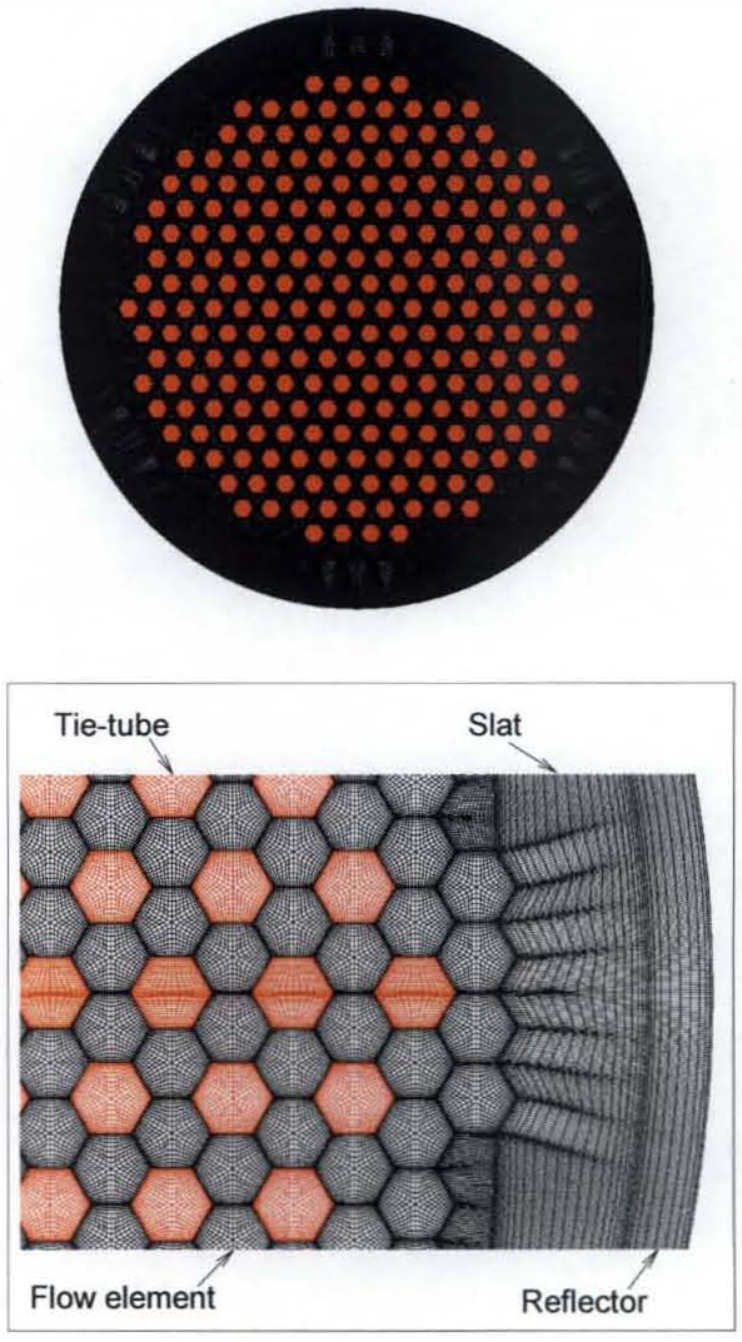

Thrust Chamber Model

\section{Small Engine Solid-core}




\section{Run matrix}

Table 2 Run matrix.

\begin{tabular}{|c|c|c|c|}
\hline Case & Axial power shape & Radial power shape & Chemistry \\
\hline 1 & Cosine & Cosine & Finite-rate \\
\hline 2 & Cosine & Cosine & Frozen \\
\hline 3 & Clipped Cosine & Flattened & Finite-rate \\
\hline 4 & Clipped Cosine & Flattened & frozen \\
\hline 5 & Clipped Cosine & Flat & Finite-rate \\
\hline
\end{tabular}




\section{Power profiles}

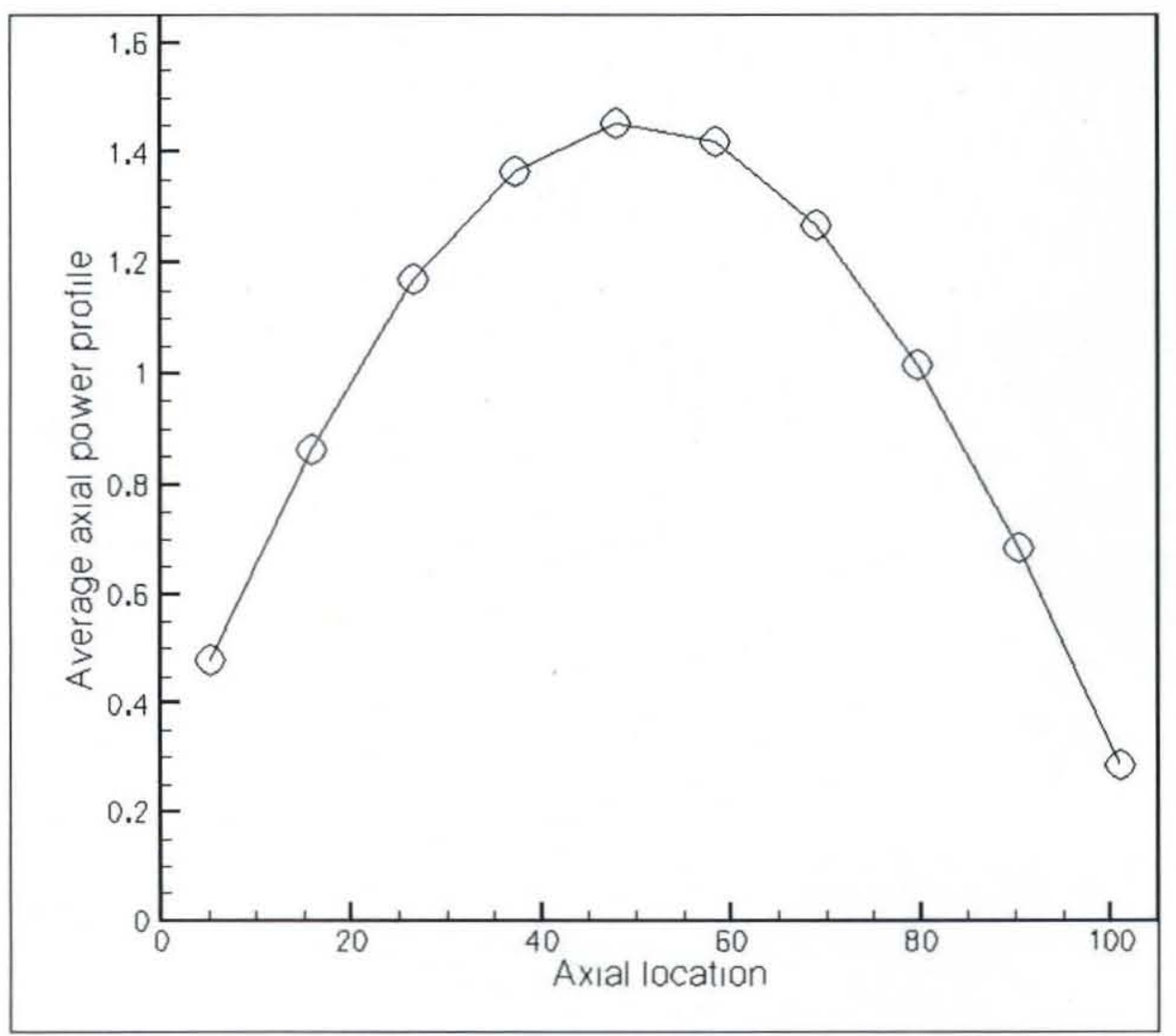

Clipped Cosine axial power profile

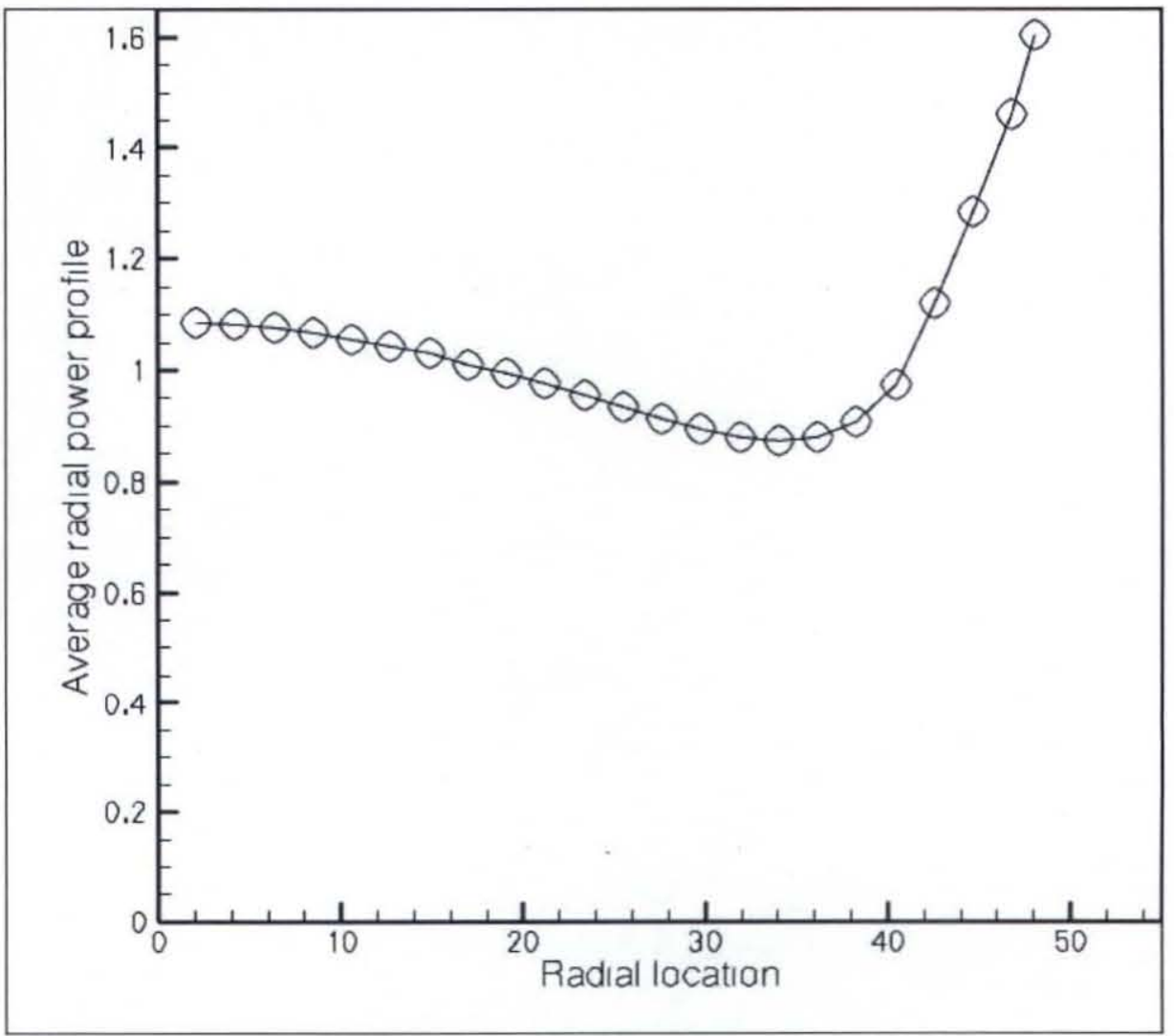

Flattened radial power profile 


\section{Solid-Core Thermal Conductivity}

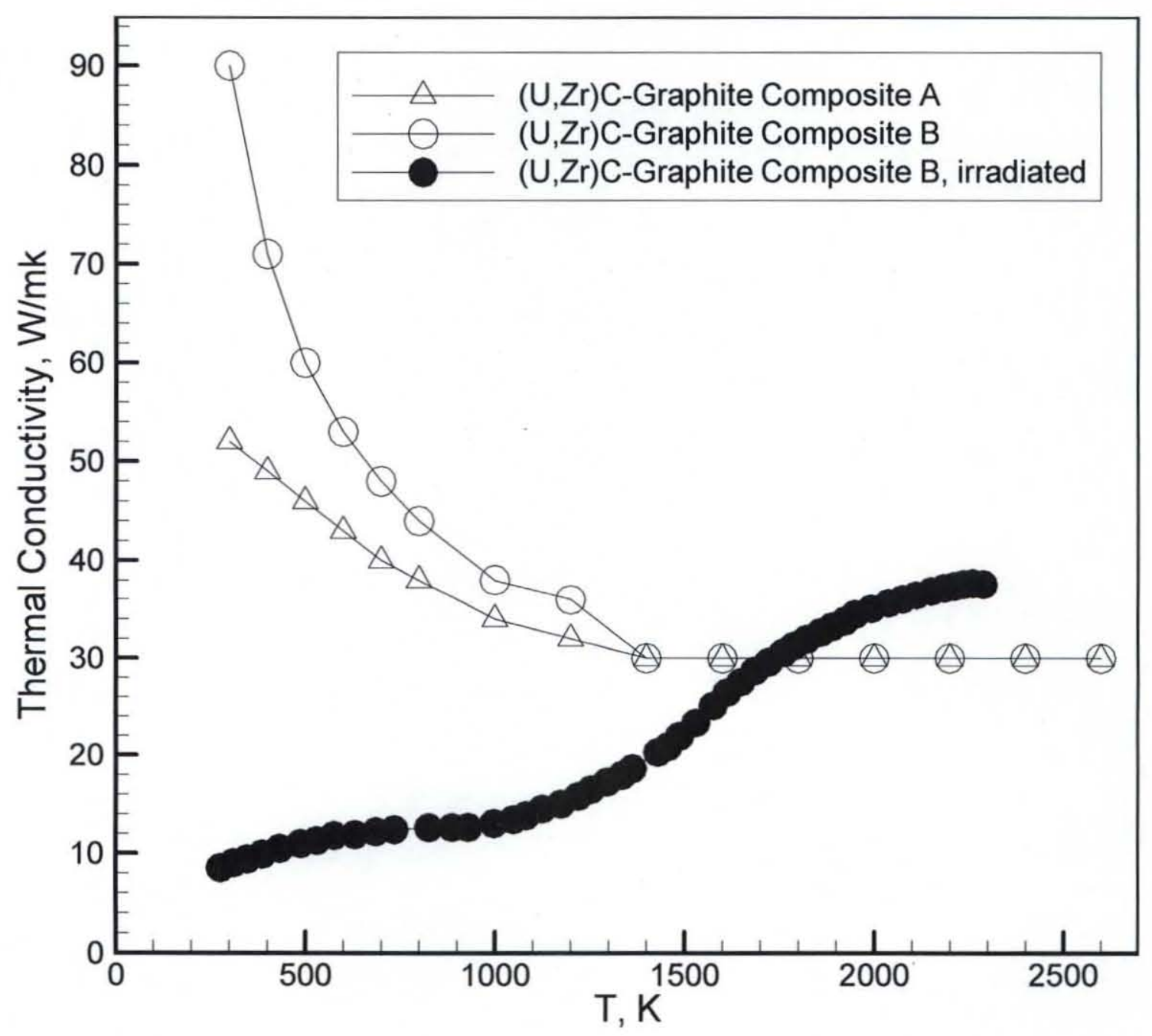




\section{Result of Global Thrust Chamber Analysis}

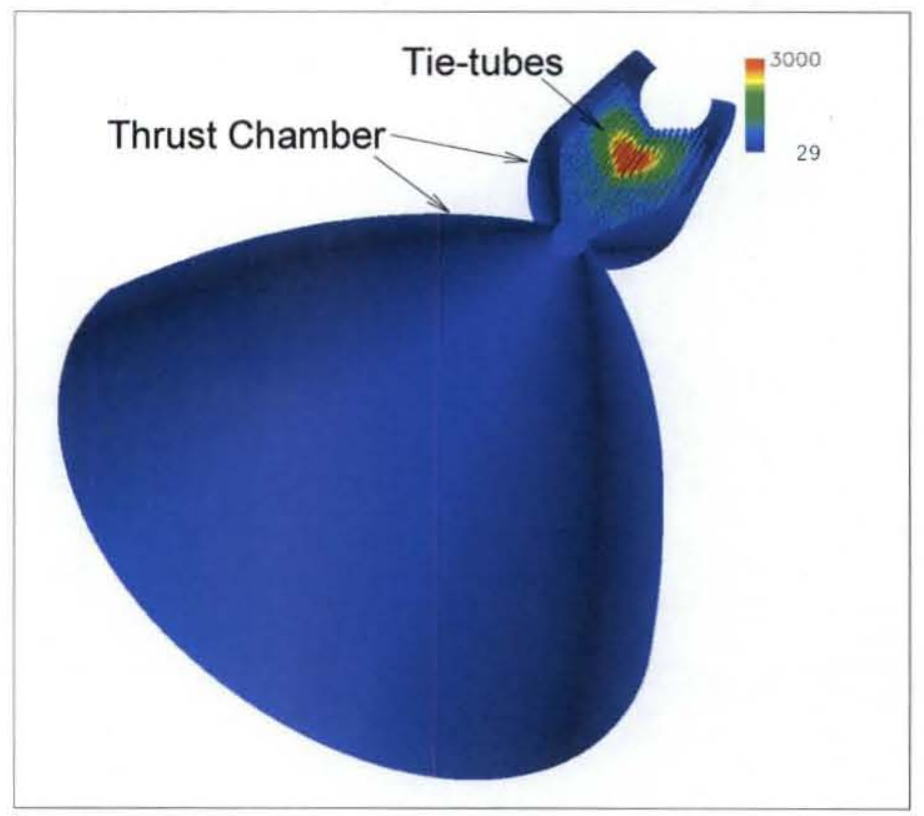

Computed Gas temperature contours on thrust Chamber and tie-tube walls
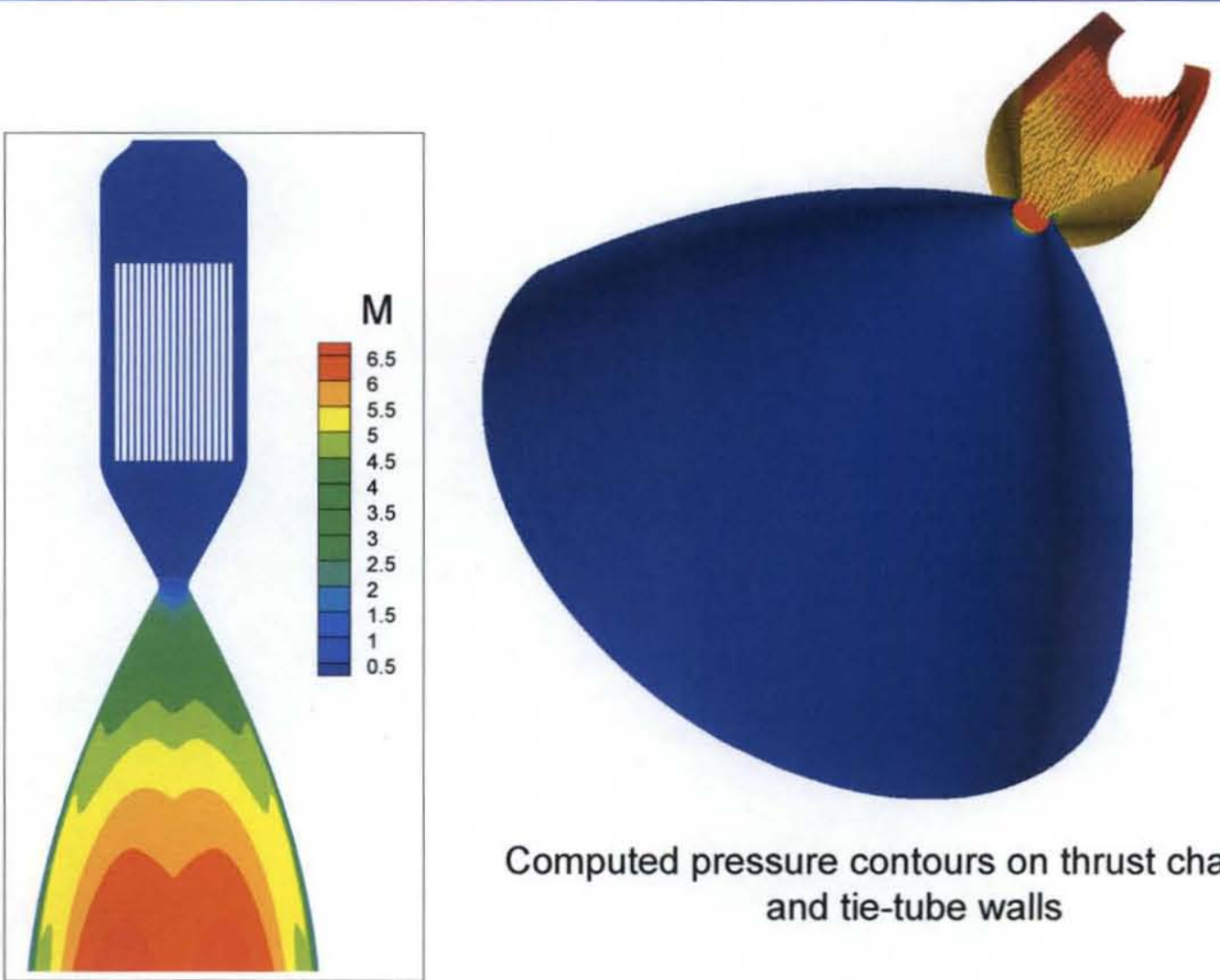

Computed pressure contours on thrust chamber and tie-tube walls
Mach number contours on symmetry plane 


\section{Result of Global Thrust Chamber Analysis}

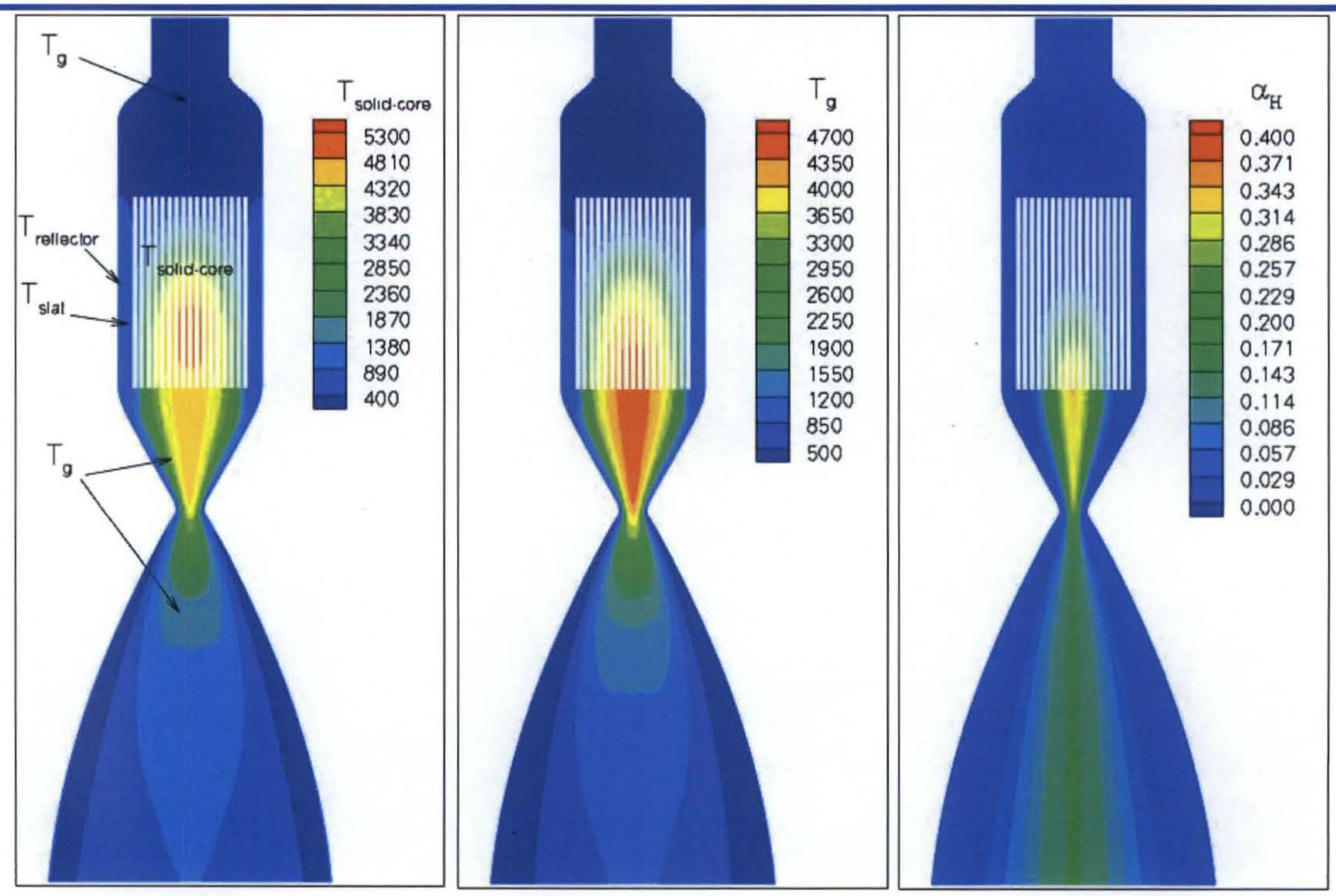

Case 1: Cosine - Cosine Power Profiles, Finite-Rate Chemistry 


\section{Result of Global Thrust Chamber Analysis}
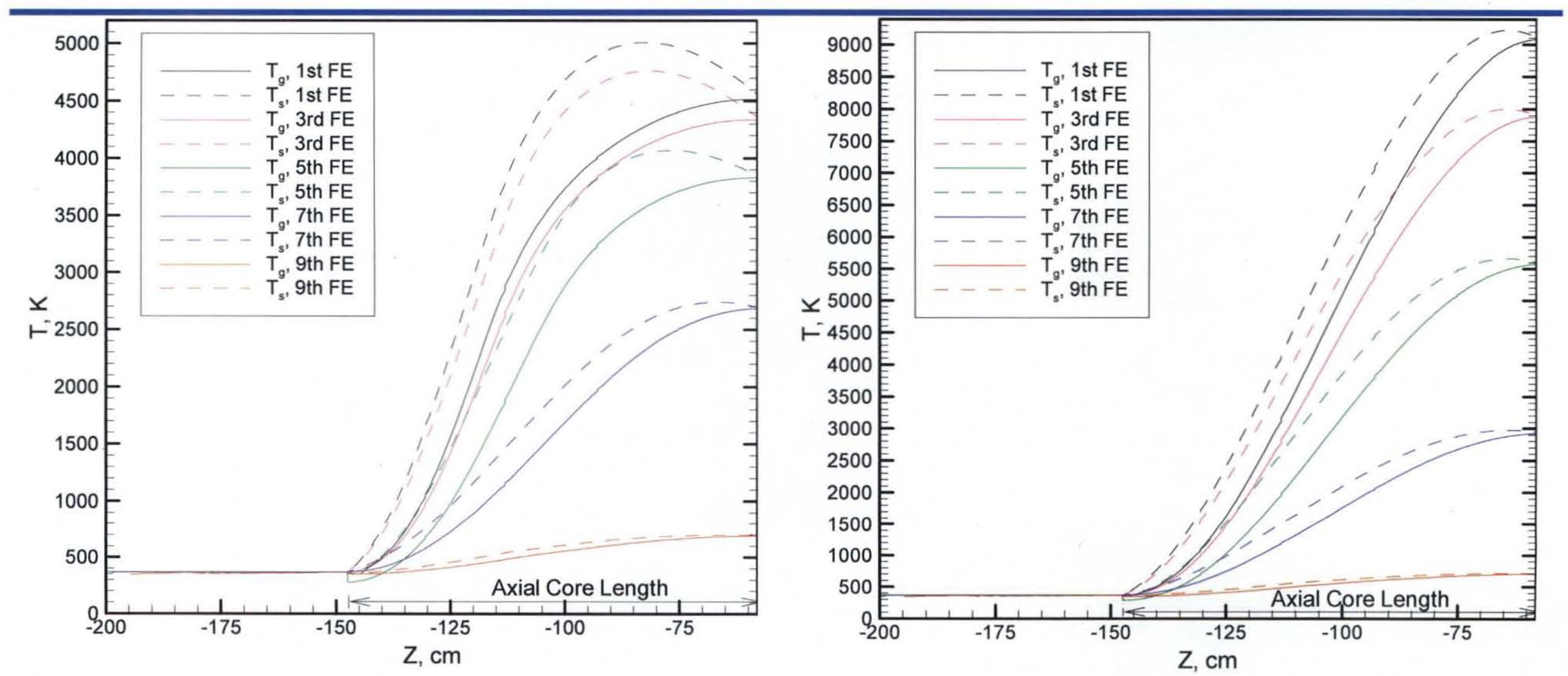

Case 1, Finite-Rate Chemistry

Case 2, Frozen Chemistry 


\section{Result of Global Thrust Chamber Analysis}
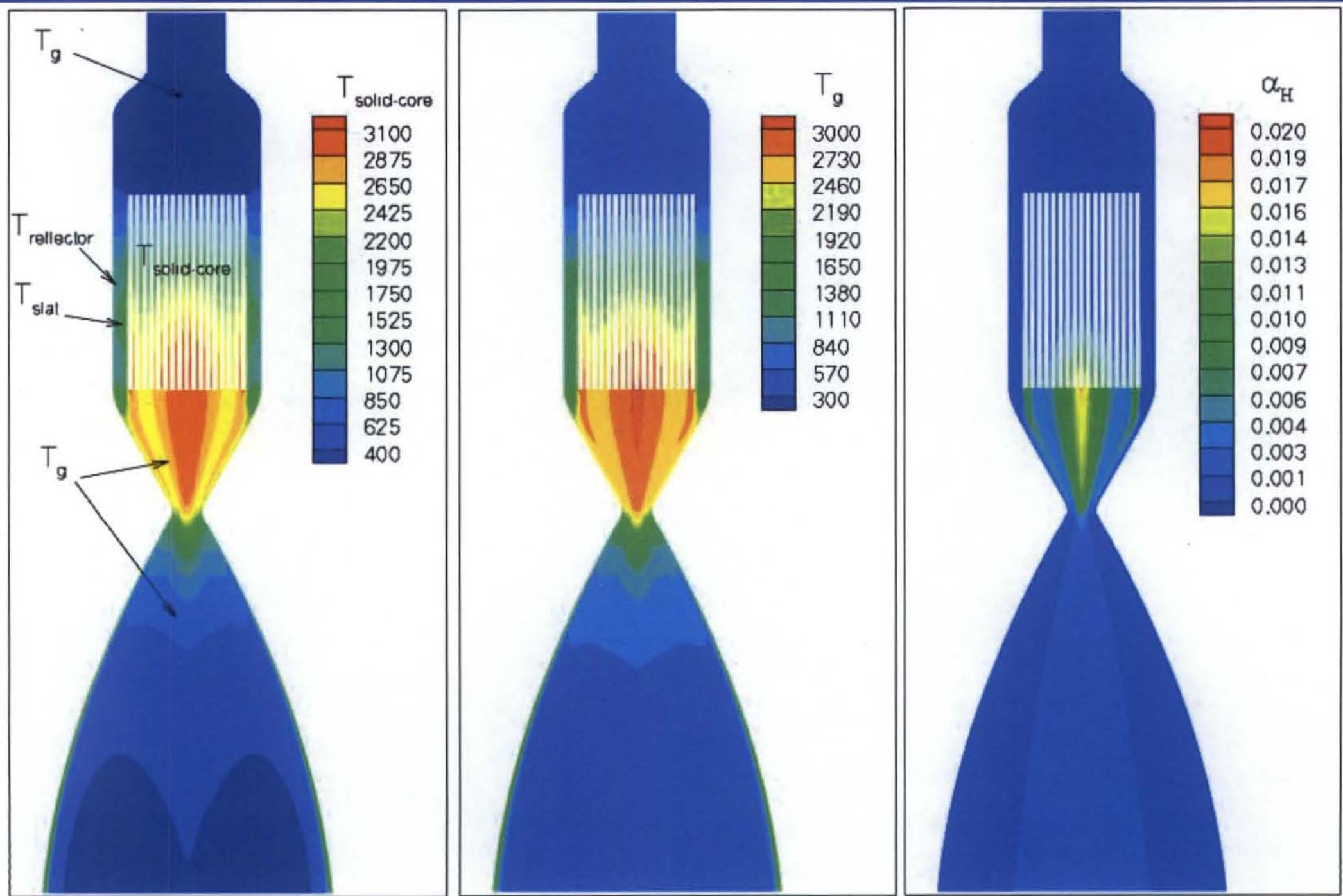

Case 3: Clipped Cosine Axial and Flattened Radial Power Profiles, Finite-Rate Chemistry 


\section{Result of Global Thrust Chamber Analysis}
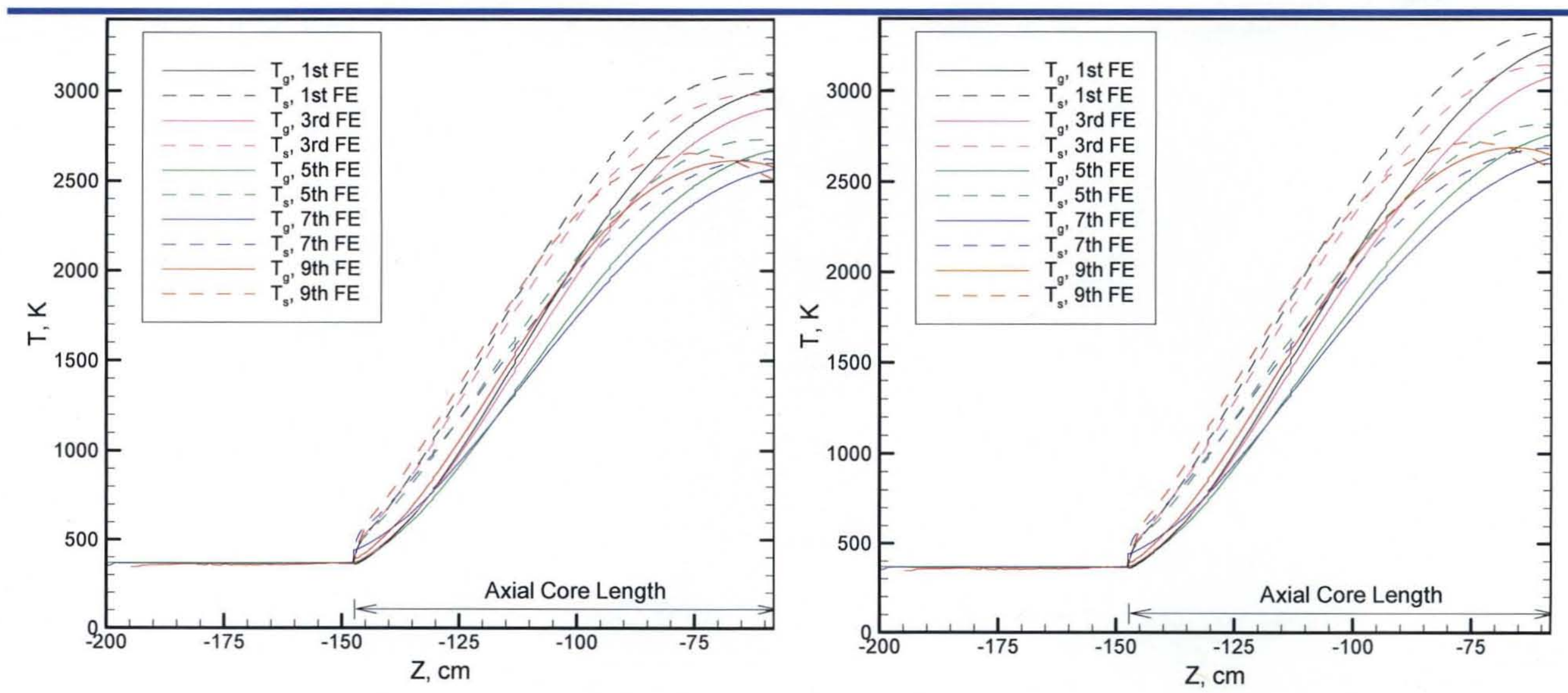

Case 3, Finite-Rate Chemistry

Case 4, Frozen Chemistry 


\section{Result of Global Thrust Chamber Analysis}

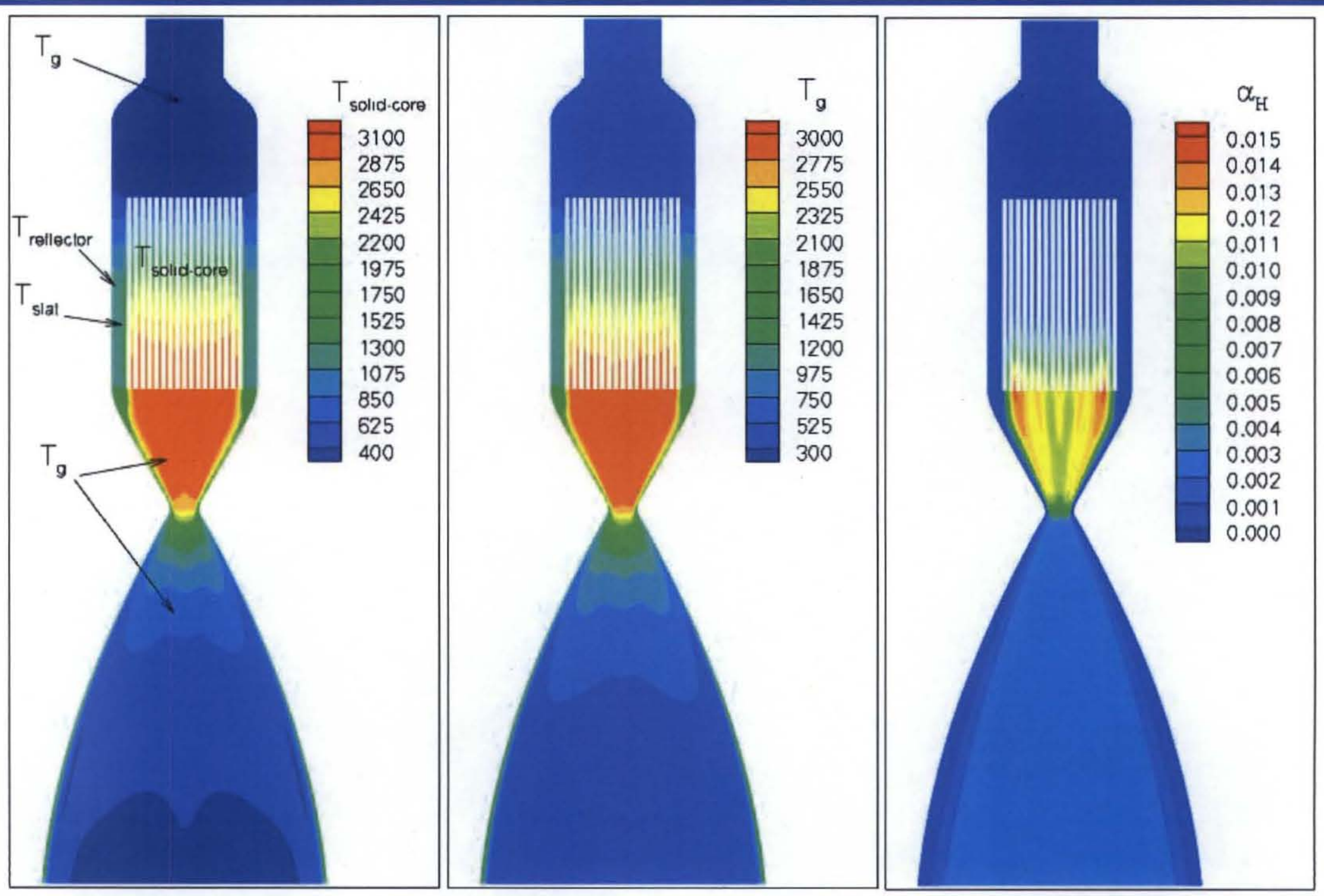

Case 5: Clipped Cosine Axial and Flat Radial Power Profiles, Finite-Rate Chemistry 


\section{Result of Global Thrust Chamber Analysis}

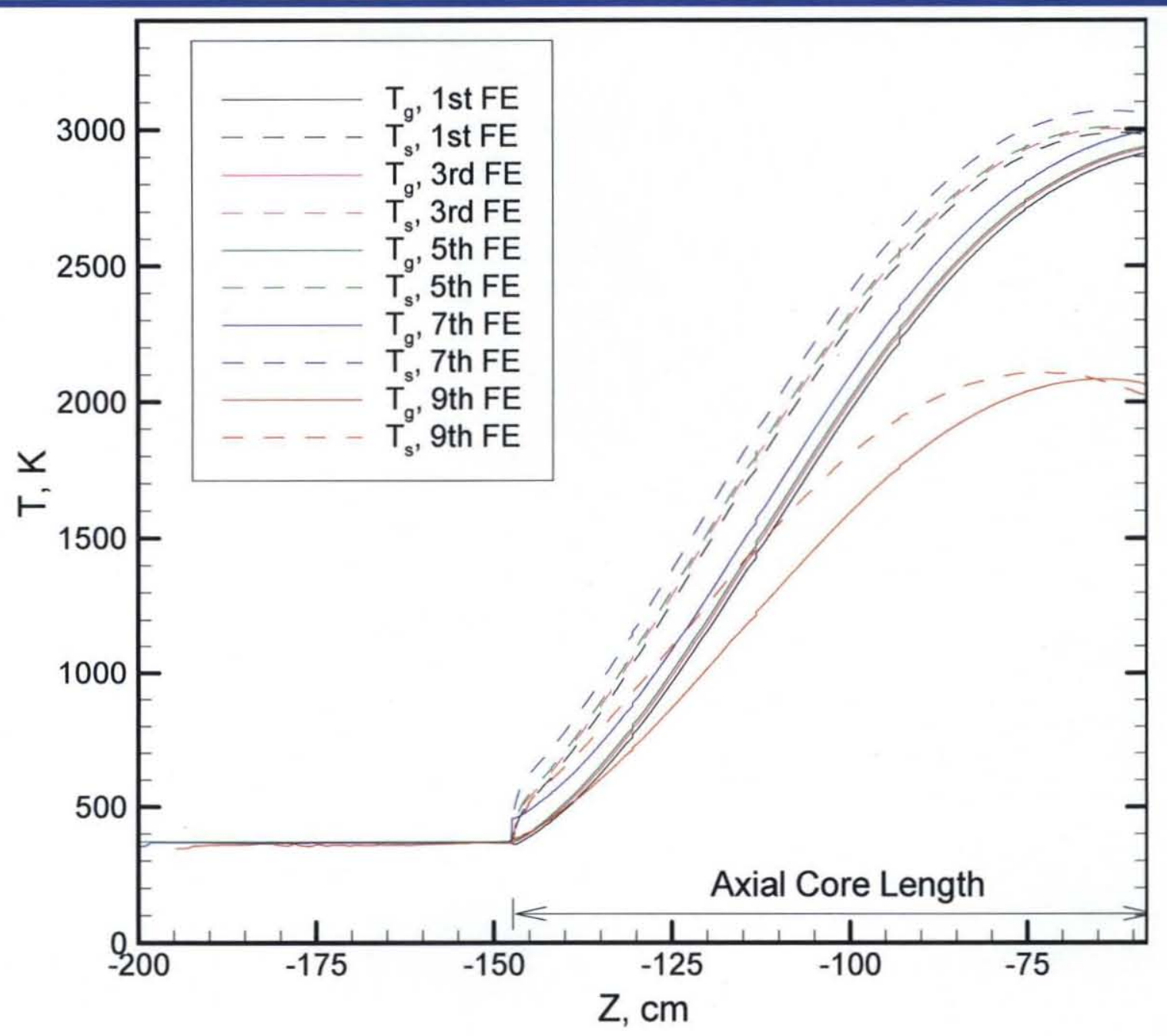

Case 5, Finite-Rate Chemistry 


\section{Result of Global Thrust Chamber Analysis}

Table 3 A summary of the heat transfer and performance parameters.

\begin{tabular}{|c|c|c|c|c|c|}
\hline Case & $\mathrm{T}_{\mathrm{g}, \text { core exit, }}, \mathrm{K}$ & $\Delta \mathrm{T}_{\mathrm{g}, \text { core exit, }} \mathrm{K}$ & $\mathrm{ISP}$ & $\Delta \mathrm{P}_{\text {core, }}, \mathrm{atm}$ & $\mathrm{T}_{\mathrm{s} \max }$ \\
\hline 1 & 3334 & 3734 & 811 & 8.9 & 5369 \\
\hline 2 & 5514 & 8329 & 844 & 8.9 & 9366 \\
\hline 3 & 2785 & 531 & 868 & 9.1 & 3149 \\
\hline 4 & 2927 & 654 & 873 & 9.1 & 3365 \\
\hline 5 & 2782 & 842 & 900 & 9.1 & 3066 \\
\hline Small Engine & 2750 & - & $860 \sim 875$ & 9.0 & \\
\hline
\end{tabular}




\section{Conclusion}

- A computational conjugate heat transfer methodology was developed to predict fluid-thermal-hydrogen environments for a hypothetical solidcore, nuclear thermal engine thruster and the associated flow element.

- A thrust chamber global analysis was performed to understand the effects of hydrogen dissociation and power profiles on heat transfer efficiency and thrust performance.

- The computed thermal-fluid-hydrogen environments and thrust performance appear to match those of the Small Engine.

- Finite-rate chemistry is important in predicting the proper energy balance as naturally occurring hydrogen is endothermic.

- High hydrogen decomposition neither improves the heat transfer efficiency, nor increasing the thrust performance. Rather, it is the more uniform power profile that produces lower peak solid temperature, higher heat transfer efficiency, and higher thrust performance. 